\title{
The Environment of Precipitating Shallow Cumulus Convection
}

\author{
LOUISE NUIJENS \\ Department of Atmospheric and Oceanic Sciences, University of California, Los Angeles, Los Angeles, California

\section{BJORN STEVENS} \\ Max Planck Institute for Meteorology, Hamburg, Germany, and Department of Atmospheric and Oceanic Sciences, \\ University of California, Los Angeles, Los Angeles, California
}

\author{
A. PIER Siebesma \\ Royal Netherlands Meteorological Institute (KNMI), De Bilt, and Department of Multi-Scale Physics, \\ Delft University of Technology, Delft, Netherlands
}

(Manuscript received 27 May 2008, in final form 26 November 2008)

\begin{abstract}
Quantitative estimates of precipitation in a typical undisturbed trade wind region are derived from 2 months of radar reflectivity data and compared to the meteorological environment determined from soundings, surface flux, and airborne-lidar data. Shallow precipitation was ubiquitous, covering on average about $2 \%$ of the region and contributing to at least half of the total precipitation. Echo fractions on the scale of the radar domain range between $0 \%$ and $10 \%$ and vary greatly within a period from a few hours to a day. Variability in precipitation relates most strongly to variability in humidity and the zonal wind speed, although greater inversion heights and deeper clouds are also evident at times of more rain. The analysis herein suggests that subtle fluctuations in both the strength of the easterlies and in subsidence play a major role in regulating humidity and hence precipitation, even within a given meteorological regime (here, the undisturbed trades).
\end{abstract}

\section{Introduction}

Precipitation from shallow cumulus clouds over subtropical oceans, commonly described as warm rain showers, has been observed in several past studies (Byers and Hall 1955; Austin et al. 1996; Petty 1999; Johnson et al. 1999); however, detailed estimates of the frequency, intensity, and areal coverage of this type of precipitation, in particular over larger areas and longer time periods, are scarce. The small area covered by these clouds (and thus the area covered by precipitation) is hard to measure using visible, microwave, and infrared sensors aboard operational satellites. Sensor footprints are often too coarse and clouds and precipitation at higher levels can easily obscure low-level clouds and precipitation near the surface.

Corresponding author address: Louise Nuijens, Dept. of Atmospheric and Oceanic Sciences, University of California, Los Angeles, 405 Hilgard Ave., Box 951565, Los Angeles, CA 90095-1565.

E-mail: Inuyens@atmos.ucla.edu
Recent studies using data from the spaceborne Tropical Rainfall Measuring Mission Precipitation Radar (TRMM PR), operational since December 1997, have indicated that shallow precipitation may contribute an appreciable amount to the total precipitation in the tropics (Short and Nakamura 2000; Schumacher and Houze 2003; Lau and $\mathrm{Wu} 2003$ ), with estimates ranging up to $20 \%$. These estimates are based on subsets of TRMM data for which the majority of radar echoes (which span at least $750 \mathrm{~m}$ in depth) have tops below $3 \mathrm{~km}$. Although the TRMM PR benefits from a high vertical resolution and low rain-rate detection (a minimum of $0.4-0.5 \mathrm{~mm} \mathrm{~h}^{-1}$ ), it is unclear how much precipitation from shallow cumulus is actually observed by TRMM. Sensitivity and resolution effects can lead to an undersampling of radar echoes at low levels, in particular at off-nadir scanning angles because of radar main lobe contamination (Short and Nakamura 2000).

The representation of shallow cumulus clouds in climate models and the role they may play in determining climate sensitivity is an ongoing topic of interest (Bony 
et al. 2004; Medeiros et al. 2008). If a significant amount of precipitation over tropical oceans is in fact from shallow cumuli, a better understanding of interactions between precipitation and a cumulus population that may determine cloud fraction and cloud optical depth (and hence cloud-radiative feedbacks) is required. Because microphysical processes were not incorporated in past modeling studies of shallow cumulus convection, several important questions are left unanswered: How much precipitation does a typical cumulus cloud produce? Do deeper cumuli rain more, and does precipitation significantly affect boundary layer dynamics? What is the influence of chemical factors (i.e., aerosols) on precipitation?

Recently, a number of large-eddy simulation (LES) studies focused specifically on precipitating shallow cumulus. A Global Energy and Water Cycle Experiment (GEWEX) Cloud System Study (GCSS) intercomparison case, based on observations from the Rain in Cumulus over the Ocean (RICO) field campaign (Rauber et al. 2007), surveys the microphysical robustness among different LES codes. Other LES studies that include microphysical processes show that increasing the humidity in the cloud layer leads to deeper clouds that rain more; however, they also indicate that precipitation itself may limit cloud growth and hence the boundary layer depth (Stevens 2007; Stevens and Seifert 2008). Aerosol-cloud interactions, discussed by Xue and Feingold (2006) and Xue et al. (2008), indicate that the response of bulk cloud parameters to changes in the aerosol is complex. For instance, in their LES study, cloud fraction decreases with increasing aerosol concentrations, opposite to the hypothesized aerosol second indirect effect, whereas aerosols may not only suppress precipitation but also lead to enhanced droplet evaporation.

Thus far, the results of several of these studies have not been compared to observations. Most modeling studies that focus on the role of aerosols use idealized cases and prescribe large-scale forcings and initial temperature, humidity, and wind profiles. To study aerosol effects, however, particularly on larger scales, one also requires an understanding of the importance of meteorological factors in controlling clouds and precipitation, hence our study. Our specific interest is to obtain a better understanding of the following: to what extent can variability in shallow precipitation be related to variability in the meteorological environment?

The extensive dataset collected during RICO, set in a typical trade wind region near the Caribbean islands of Antigua and Barbuda for a period slightly over 2 months, offers the opportunity to address this question from an observational point of view. A ground-based radar (SPolKa), scanning an area up to $150 \mathrm{~km}$ in radius, measured precipitation-related quantities with high resolution in both space and time. In addition, a variety of airborne, ship-based, and land-based measurements were taken. Our objectives in this paper are twofold: first, to present quantitative estimates of precipitation from shallow trade wind cumuli (section 3 ) and second, to discuss precipitation variability in relation to variability in the meteorological environment (section 4).

\section{Data and methodology}

\section{a. Data}

All data used in this study were collected in the close vicinity of the Caribbean islands of Antigua and Barbuda, mainly in a region upwind (northeast) of Barbuda (Fig. 1). RICO operations lasted for 63 days, starting on 24 November 2004 and ending on 25 January 2005. A detailed overview of all operations and their time frames can be found in Rauber et al. (2007). A weather summary by Caesar (2005) describes the meteorological conditions during RICO as typical for this region and time of year, with a cloud field dominated by shallow cumulus clouds organized as bands, clusters, and isolated scattered cells. A few tropical waves, low- and upper-level troughs, and weak cold fronts were present, but less than $5 \%$ of the total period was overcast or dominated by heavy precipitation associated with such disturbances. These disturbed periods are excluded from the analysis, as described in section $2 b$.

\section{1) RADAR REFLECTIVITY DATA}

Radar reflectivity data are obtained from measurements by the ground based S- and K-band dual polarization radar (SPolKa), located on Barbuda $\left(17.6^{\circ} 36.448^{\prime} \mathrm{N}\right.$, $\left.61^{\circ} 49.457^{\prime} \mathrm{W}\right)$. The radar, with a beamwidth of $0.91^{\circ}$, performed scanning routines at several elevation angles, from $0.5^{\circ}$ up to $16.5^{\circ}$ with a $1^{\circ}$ increment. Only the S-band (10.68-cm wavelength) data for the surveillance scans (the $360^{\circ}$ scans taken at the $0.5^{\circ}$ elevation angle that have a maximum range of $150 \mathrm{~km}$ ) are used in the present study. These scans were performed approximately every $20 \mathrm{~min}$, resulting in about 70 scans per day and a total of 3662 scans during RICO. Each scan is regridded onto a polar grid with a mesh of $150 \mathrm{~m}$ (in range) and $0.67^{\circ}$ (in azimuth angle), comprising $984 \times 540$ pixels in total.

To exclude noise and anomalous returns from ground and sea clutter, birds, etc., the scans are subjected to a multitiered filtering procedure. Histograms of unfiltered and filtered data are compared to evaluate each filtering procedure (not shown). First, radar noise (identified as 


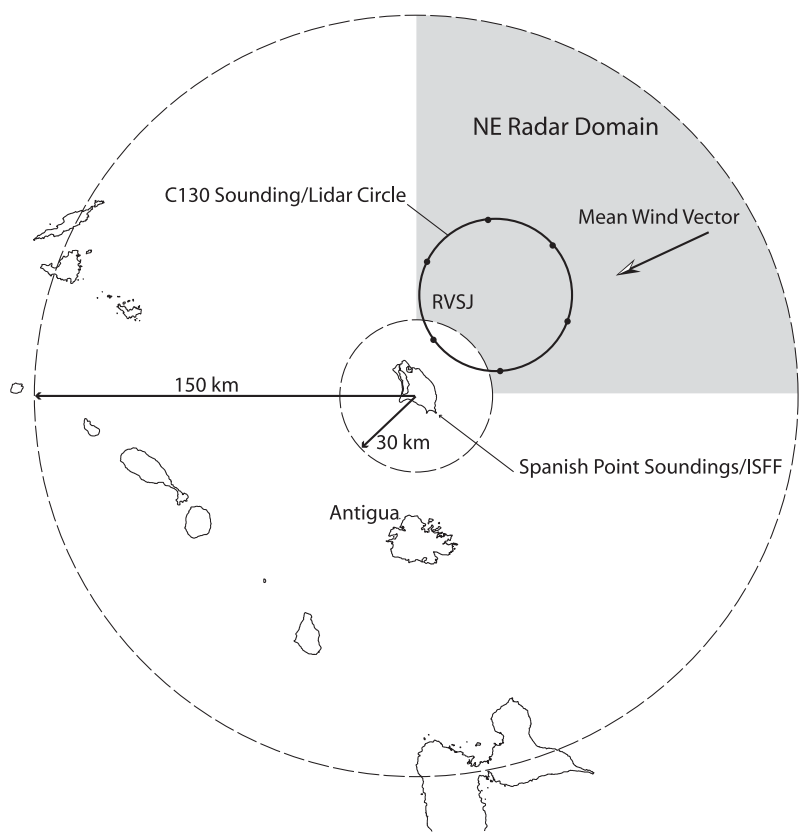

FIG. 1. Scheme indicating the $150-\mathrm{km}$ radius domain of the SPolKa radar, located on Barbuda. Also shown are Spanish Point (sounding/ISFF site) and the northeast domain in which aircraft (C130) and ship (RVSJ) operations were performed.

pixels with a received radar power less than $-115 \mathrm{dBm}$ ) and ground clutter (identified by island pixels that experience high reflectivities at the exact same coordinates in each scan) are removed. Second, pixels with differential reflectivity values outside an acceptable range of -1.5 to $-3 \mathrm{~dB}$ (arising from objects with degrees of anisotropy much larger than expected from a raindrop) are removed. Third, pixels within a close range of the radar $(<60 \mathrm{~km})$ showing irregular radial velocities or single isolated pixels with high reflectivities, presumably associated with birds and sea clutter, are removed as well. Fourth, a reflectivity threshold of $7 \mathrm{dBZ}$ is used to exclude Bragg scattering returns caused by turbulent fluctuations in the refractive index of air due to humidity and temperature, for instance near the trade inversion or cloud edges. The 7-dBZ threshold is loosely based on findings from Knight and Miller (1993, 1998), who investigated the magnitude of Bragg scattering returns in and near clouds by considering theoretical expressions of the returned radar power from either hydrometeor or index of refraction variations; they suggest $10 \mathrm{dBZ}$ as a safe threshold above which Bragg scattering is negligible. Note that some hydrometeor scattering (e.g., from light drizzle) may be removed using the 7-dBZ threshold, hence estimates presented here likely underestimate the amount of rainfall from cumulus. Although the term "radar echo" is commonly used for any signal on a radar scan other than noise, it refers in our paper only to those pixels that survived the filtering procedure.

Within $30 \mathrm{~km}$ of the radar, azimuthal average reflectivities deviate significantly from values beyond $30 \mathrm{~km}$. A reflectivity maximum is present within a $15-\mathrm{km}$ range and may be explained by the presence of very small echoes, possibly noise or birds not captured by the filtering procedure. Trivej and Stevens (2009, manuscript submitted to J. Atmos. Sci.) show that the number of echoes close to the radar are anomalously high (their Fig. 10a). In our analysis only data beyond a $30-\mathrm{km}$ radius are used. At $30 \mathrm{~km}$, the radar beam roughly scans a layer from the surface to $500 \mathrm{~m}$ above sea level, sampling precipitation in the subcloud layer. Beyond this range, the beam geometry is such that precipitation both below and in clouds is sampled. Beam broadening and changes in reflectivity with height, associated with the evolution of the hydrometeor size spectrum within the rain shaft, contribute to a general decrease of the azimuthal average reflectivity of about $2 \mathrm{dBZ}(100 \mathrm{~km})^{-1}$. Because we do not correct for such effects, this will lead to uncertainties in the derivation of area-average rainfall rates (Joss and Lee 1995); however, as further described in section $3 \mathrm{c}$, our analysis focuses on the areal coverage of rainfall, so these uncertainties are not expected to affect the overall conclusions.

In addition to radar reflectivity data, the radial (Doppler) velocity data is used to analyze the horizontal wind field. Radial velocities are averaged into concentric rings, each covering a range of $\sim 22 \mathrm{~km}$, and Fourier analysis is applied to get the best-fitting sinusoid to each ring, with the amplitude and phase corresponding to the (approximately horizontal) ambient wind speed and wind direction.

\section{2) SOUNDING DATA}

A total of 421 soundings are available from a variety of locations: 144 GPS Advanced Upper Air Sounding System (GAUS) radiosondes from Spanish Point (SPNT), a spit of land on the southeastern shore of Barbuda (Fig. 1), 83 soundings from the research vessel Seward Johnson (RVSJ) and 194 dropsondes from the National Science Foundation (NSF)-National Center for Atmospheric Research (NCAR) C130 aircraft (C130). The SPNT soundings were launched between 7 December and 24 January with a frequency of 2-4 soundings per day. The RVSJ soundings were launched from 3 January onwards, typically with 6 to 8 soundings per day, while cruising an area north-northeast of Barbuda during January, except for a few days when the ship took up station at Antigua or stayed on the leeside of Barbuda. The $\mathrm{C} 130$ aircraft released six to nine dropsondes while flying free tropospheric circles (at $\sim 4500 \mathrm{~m}$ ) of roughly 
$60 \mathrm{~km}$ in diameter. These circles were performed twice, near the beginning and the end of almost every 8-h flight. On research flight 1 (RF01) (7 December) and RF16 (18 December) no full second circle was performed. All circles were flown in an area northeast of Barbuda within a 150-km range from the radar, except for RF06. The $\mathrm{C} 130$ dropsondes are combined into an average sounding for each circle (hereafter referred to as $\mathrm{C} 130 \mathrm{C})$. Combined, the soundings are distributed as follows (in terms of number of soundings per day): two to six soundings from 7-20 December, two (occasionally one) soundings from 21 December to 2 January, and two to ten soundings from 3-25 January.

The Spanish Point sondes have been subjected to an automated quality control check by the Earth Observing Laboratory's (EOL's) Atmospheric Sounding Processing Environment (ASPEN). A temperature radiation correction is applied to remove unrealistic temperature gradients due to radiation processes, and a lowpass wind filter removes pendulum motions beneath the balloon. Additional quality checks are applied, following analyses described in Yin and Albrecht (2000) and Sobel et al. (2004), to create a consistent dataset without data gaps below $600 \mathrm{hPa}$, corresponding roughly to the level at which $\mathrm{C} 130$ dropsondes were released $(\sim 550 \mathrm{hPa})$. Eighteen soundings with missing pressures at all levels, unrealistic high relative humidity (RH) after cloud penetration, or gaps greater than $50 \mathrm{hPa}$ are excluded. The remaining 246 soundings are visually inspected to ensure consistency between the three datasets on any given day. The 2-month average SPNT sounding does not differ much from the 2-month average of all SPNT, RVSJ, and C130C soundings, and it is assumed that the dataset does not particularly emphasize the atmospheric conditions during January.

The soundings are regridded on a constant pressure grid starting at the surface and decreasing with a 2-hPa increment. Data are set to "missing value" when pressure changes in the opposite direction of the sonde motion, and data gaps smaller than $10 \mathrm{hPa}$ are interpolated.

\section{3) Surface Flux DATA}

Sea surface temperature and surface flux measurements performed by the ship (RVSJ) are available as 30-min statistics, but only for 3-25 January. To obtain surface flux data for the full 2-month period, data collected at the Integrated Surface Flux Facility (ISFF) meteorological station, located on Spanish Point, Barbuda (coincident with the sounding site), are used to estimate open sea fluxes. These data include 5-min statistics of air temperature and relative humidity at $2 \mathrm{~m}$ AGL (Vaisala 50Y Humitters), pressure (Vaisala
PTB220 barometer), and wind speed and wind direction at $10 \mathrm{~m}$ AGL (RM Young prop vane) for 4 December25 January (53 days in total). In addition, daily sea surface temperatures used as boundary condition of the European Centre for Medium-Range Weather Forecasts (ECMWF) Integrated Forecast System (IFS; Reynolds et al. 2002) are used to derive ISFF surface fluxes. This is performed using flux profile relationships similar to the Coupled Ocean-Atmosphere Response Experiment (COARE) 3.0 bulk air-sea flux algorithm Fairall et al. (2003).

Differences between the ISFF and RVSJ fluxes are expected because of a strong diurnal cycle in the ISFF temperature. During the night, the ISFF sensible heat fluxes are considerably higher because of stronger cooling of the air just above the surface (and the same SST estimate is used for both day and night), and the opposite is true for the fluxes during the day. After removing high-frequency signals $(<26 \mathrm{~h})$ in temperature from the ISFF and RVSJ data, a reasonable agreement among sensible heat fluxes (given the small magnitude of the signal) and a good agreement among latent heat fluxes are obtained (Fig. 2). To test whether remaining differences are caused by using different SSTs, the fluxes for January are derived using RVSJ SST estimates instead, but changes are minimal. For these reasons we believe the ISFF provides a useful estimate of the open sea fluxes for the full 2-month period.

\section{4) LIDAR DATA}

Data from the NCAR aerosol backscatter lidar, which operated at 532 and $1064 \mathrm{~nm}$ aboard the C130 aircraft, are used to derive cloud top height distributions. The lidar data are analyzed for all free tropospheric circles for flights RF01 and RF03-RF19 (see also section $2 \mathrm{~b}$ ), when the lidar was pointing at nadir. Cloud top is identified as the first return (at $1064 \mathrm{~nm}$ ) that exceeds a given threshold (in this case $18 \mathrm{~dB}$ ), and cloud top heights are estimated by using the measured range from aircraft, the aircraft altitude, and its orientation (to account for slight offsets from nadir pointing).

\section{b. Methodology}

In our analysis, a distinction is made between the full set of radar data (I) and a subset of the radar data (II), from which scans on 6 days with disturbed conditions are excluded. Using the echo fraction $F$, which represents the area covered by echoes on a radar scan and is used as a proxy for precipitation for reasons detailed in section $3 c$, these 6 disturbed days are identified by the following procedure: Scans with echo fractions deviating more than three standard deviations from the mean echo fraction of dataset $\mathrm{I}\left(\overline{F^{\mathrm{I}}}=0.031\right)$ are set to missing 

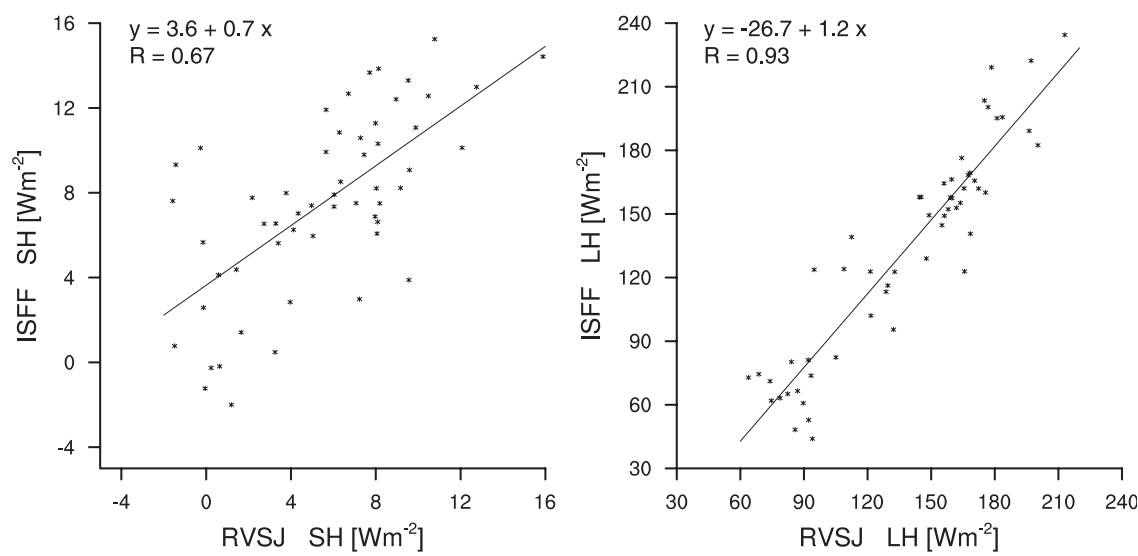

FIG. 2. Six-hour averages of (left) sensible and (right) latent heat flux are plotted for ISFF vs RVSJ [see section 2a(3)] using data from 3-25 Jan 2005, where all frequencies $<26$ h have been removed.

value and the mean is recalculated $(\bar{F}=0.023)$. This procedure is repeated for scans that deviate more than three standard deviations from $\bar{F}=0.023$. All scans set to missing value are distributed over the 6 days summarized in Table 1. Dataset II excludes all scans on these 6 days (354 scans) and is assumed to represent undisturbed trade wind conditions $\left(\overline{F^{\mathrm{II}}}=0.02\right)$. Although, our analysis focuses mostly on undisturbed conditions, dataset I is used for the general overview of precipitation during RICO in section 3 .

A third dataset (III) is created to explore relations between precipitation and meteorology. It combines dataset II with sounding and surface flux data, excluding 31 soundings and $\sim 10 \%$ of surface flux data on the disturbed 6 days, and focuses only on the echo fraction in the northeast segment of the radar domain, denoted by $f$, where most meteorological data were collected. This also eliminates a possible influence of the islands on downwind precipitation statistics. For consistency, 18 soundings (16 RVSJ and two C130C soundings) released outside of the northeast segment (approximately $17.6^{\circ}-18.6^{\circ} \mathrm{N}$ and $60^{\circ}-61^{\circ} \mathrm{W}$ ) are excluded as well because

TABLE 1 . The daily average echo fraction, wind speed, wind direction (derived from radial velocity data), and mean relative humidity between 900 and $700 \mathrm{hPa}$ (from the daily mean sounding) for 6 days during RICO identified as "disturbed days" (section 2b).

\begin{tabular}{ccccc}
\hline \hline Date & $\bar{f}^{d}$ & $\begin{array}{c}\text { Wind speed } \\
\left(\mathrm{m} \mathrm{s}^{-1}\right)\end{array}$ & $\begin{array}{c}\text { Wind } \\
\text { direction }\left(^{\circ}\right)\end{array}$ & RH $(\%)$ \\
\hline 13 Dec 2004 & 0.15 & 9.0 & 72 & 82 \\
14 Dec 2004 & 0.13 & 8.5 & 91 & 93 \\
15 Dec 2004 & 0.18 & 7.5 & 101 & 89 \\
9 Jan 2005 & 0.09 & 8.9 & 70 & 84 \\
10 Jan 2005 & 0.17 & 9.8 & 80 & 77 \\
13 Jan 2005 & 0.08 & 12.7 & 77 & 81 \\
\hline
\end{tabular}

they are notably different from soundings released within the northeast segment at approximately the same time.

The sounding, surface flux, and lidar data in dataset III are composites based on a 6-h average echo fraction over the northeast radar segment $\bar{f}$. The 6 -h period is a compromise between the 11-h (lag) autocorrelation period of echo fraction (the period after which subsequent rain events become uncorrelated) and the time it takes for an air mass to advect through the northeast radar domain $(3 \mathrm{~h})$. The compositing makes use of three or six categories, depending on the amount of detail that is worth showing, and the thresholds of $\bar{f}$ are chosen such that an equal number of events is used in each composite. For the soundings, $\bar{f}$ is centered at the release time of each sounding and only the $T, \theta, q$, and surface pressure fields are averaged, from which other fields (RH, $T_{v}, \theta_{v}$, and $\theta_{e}$ ) are recomputed using a $1000-\mathrm{hPa}$ reference pressure. The surface flux data are averaged over $6 \mathrm{~h}$, giving a total of $(53-6)$ days $\times 4=188$ data points, and then compared to $\bar{f}$ during the same $6 \mathrm{~h}$.

All datasets are summarized in Table 2. The notation is as follows: echo fractions for the full and northeast radar domain are denoted by $F$ and $f$, respectively. The overbar indicates a temporal average continuous in time (such as a daily average $\bar{f}^{d}$ ), whereas brackets denote a composite mean $\langle\bar{f}\rangle$ (an average not continuous in time). The 6-h average of $f$ is most frequently used and is simply referred to as $\bar{f}$.

\section{Precipitation}

What are typical rain rates for shallow cumulus and are they significant? How frequently does precipitation occur? These questions are addressed by presenting precipitation statistics and related quantities. Relations 
TABLE 2. The number of radar scans, soundings, and surface data; details of the domain; and the symbols for echo fraction (with its mean value) and area-average rainfall (with its mean value in $\mathrm{mm} \mathrm{h}^{-1}$ and $\mathrm{W} \mathrm{m}^{-2}$ ) of the datasets used in sections $3 \mathrm{a}$ and $3 \mathrm{~b}$ (I and II), $4 \mathrm{a}-\mathrm{c}$ (III), and 4d (IV).

\begin{tabular}{|c|c|c|c|c|c|}
\hline & Dataset & Type of data & Domain & Echo fraction & $\begin{array}{c}\text { Area rainfall } \\
\left(\mathrm{mm} \mathrm{h}^{-1} / \mathrm{W} \mathrm{m}^{-2}\right)\end{array}$ \\
\hline I & Precipitation & Radar scans (3662) & Full & $\begin{array}{c}F \\
\bar{F}^{\mathrm{I}}=0.03\end{array}$ & $\begin{aligned} & R \\
\bar{R}^{\mathrm{I}}= & 0.05 / 35\end{aligned}$ \\
\hline II & Precipitation & Radar scans (3308) & $\begin{array}{l}\text { Full } \\
\text { Undisturbed }\end{array}$ & $\bar{F}^{\mathrm{II}} \stackrel{F}{=} 0.02$ & $\bar{R}^{\mathrm{II}}=\begin{array}{l}R \\
0.03 / 21\end{array}$ \\
\hline III & Composites & $\begin{array}{l}\text { Radar scans (3308) } \\
\text { Soundings (197) } \\
\text { Surface data (188) }\end{array}$ & $\begin{array}{l}\mathrm{NE} \\
\text { Undisturbed } \\
\text { 6-h average }\end{array}$ & $\bar{f}$ & - \\
\hline \multirow[t]{2}{*}{ IV } & $\begin{array}{l}\text { Daily precipitation } \\
\text { and winds }\end{array}$ & Radar scans (3308) & $\mathrm{NE}$ & $\bar{f}^{d}$ & \\
\hline & & Soundings (197) & $\begin{array}{l}\text { Undisturbed } \\
\text { 24-h average }\end{array}$ & & - \\
\hline
\end{tabular}

between precipitation and the meteorological environment will be explored in section 4 .

\section{a. Intensity and frequency of precipitation}

\section{1) FROM REFLECTIVITY TO PIXEL RAIN RATES}

The reflectivity $Z_{i}\left(\mathrm{~mm}^{6} \mathrm{~m}^{-3}\right)$ of each radar pixel is converted to a pixel rain rate $R_{i}\left(\mathrm{~mm} \mathrm{~h}^{-1}\right)$ using the TRMM $Z-R$ relationship for convective rainfall near the surface: $Z=148 R^{1.55}$ Because observations of shallow precipitation are scarce, few $Z-R$ relationships in the literature are specifically tuned to this type of precipitation. The TRMM $Z-R$ is chosen because it facilitates a comparison of satellite- and ground-based radar observations and leads to average rain rates well within the range of rain rates obtained from a variety of relations, at both high and low reflectivities. Using the TRMM $Z-R$, the Bragg filtering threshold of $7 \mathrm{dBZ}$ corresponds to a minimum rain rate of $0.11 \mathrm{~mm} \mathrm{~h}^{-1}$; similarly, 15,20 , and $25 \mathrm{dBZ}$ correspond to $0.4,0.8$, and $1.6 \mathrm{~mm} \mathrm{~h}^{-1}$, respectively. Note that $Z-R$ relationships used in two previous studies of RICO radar data are 1) $Z=248 R^{1.75}$ (Nuijens 2005) and 2) $Z=88.7 R^{1.52}$ (Snodgrass 2006; Snodgrass et al. 2009), the latter is derived from drop size spectra measured during one of the RICO $\mathrm{C} 130$ flights. Using the first value, reflectivities of 7 and $40 \mathrm{dBZ}$ are converted to rain rates that are $4 \%$ and $45 \%$ lower, respectively, than if the TRMM $Z-R$ is used. Similarly, the second value leads to rain rates that are $35 \%$ and $48 \%$ higher. Such differences introduce uncertainties of at least a few tens of percent when estimating the mean area rainfall during RICO [see section 3b(3)].

The probability density function (PDF) of pixel rain rates $R_{i}$, which is really a conditional PDF for $Z_{i}>7$ $\mathrm{dBZ}$ or $R_{i}>0.11 \mathrm{~mm} \mathrm{~h}^{-1}$, is plotted as a solid line in
Fig. 3a. The probability density falls off rapidly to rain rates of about $0.5 \mathrm{~mm} \mathrm{~h}^{-1}$, with a corresponding cumulative probability of 0.5 (Fig. $3 b$ ). The minimum detectable reflectivity by the TRMM radar is $17 \mathrm{dBZ}$, roughly 0.4-0.5 $\mathrm{mm} \mathrm{h}^{-1}$, and implies that TRMM could have detected up to half of the precipitation measured by SPol.

\section{2) FREQUenCy of PRECIPITATION}

A time series of echo fraction gives a first impression of the frequency of precipitation during RICO (Fig. 4). The echo fraction is defined as

$$
F=\frac{\sum_{i=1}^{N}\left(I_{i} r_{i}\right)}{\sum_{i=1}^{N} r_{i}}, \quad I_{i}= \begin{cases}1 & Z_{i} \geq 7 \mathrm{~dB} Z \\ 0 & Z_{i}<7 \mathrm{~dB} Z\end{cases}
$$

and represents the fraction of the total area that is covered with echoes, taking into account the increase of a pixel area with range due to the nonequidistant grid, where $r$ is the distance from the radar, so that $r_{i} \Delta r \Delta \phi$ represents the area covered by each pixel $i$, with $\Delta r=$ $150 \mathrm{~m}$ and $\Delta \phi=0.67^{\circ}$, and $N$ is the total number of pixels between $r=30-150 \mathrm{~km}$ and $0^{\circ}<\phi<360^{\circ}$, excluding the pixels marked as land.

Aside from a few disturbed events where echo fractions largely exceed 0.1 , on 13 and 15 December and 9 January, smaller rainfall events are ubiquitous, which is particularly evident when zooming in on the period between 16 December and 8 January when shallow cumulus dominated the cloud field. The mean echo fraction of such undisturbed periods is roughly 0.02 (dataset II). Given a typical cloud fraction of 0.1 to 0.2 from LES studies of shallow cumulus (Siebesma et al. 2003), one can infer that on average about one-tenth of the cloudy areas had rain. 
a)

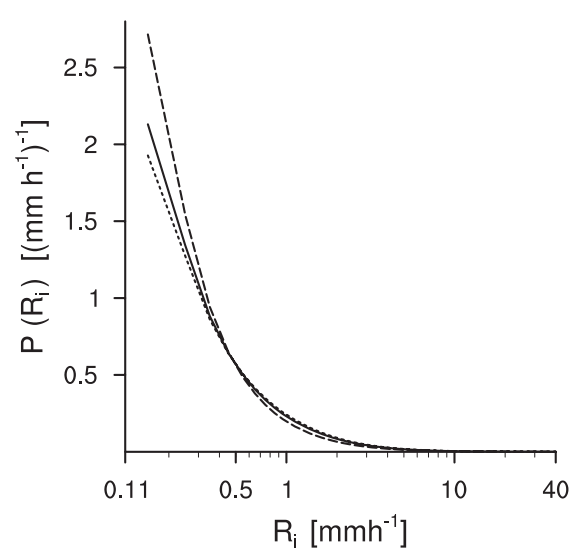

b)

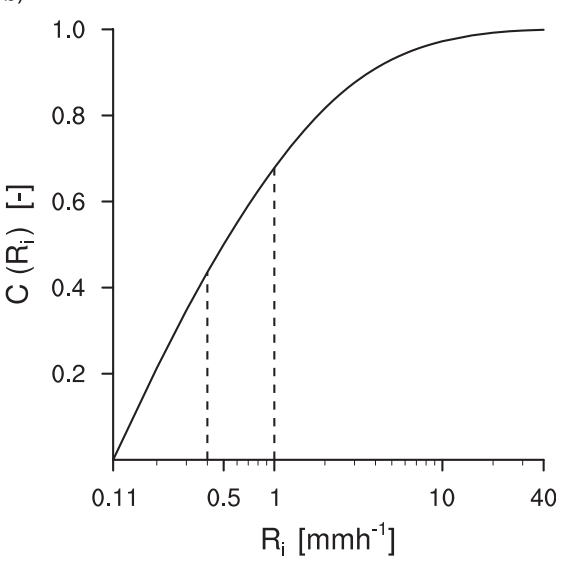

FIG. 3. (a) PDFs of pixel rain rate $P\left(R_{i}\right)$ (i.e., the probability divided by the bin width, which for bins $<1 \mathrm{~mm} \mathrm{~h}^{-1}$ can be $>1$ ). The solid line is the PDF conditioned on $Z_{i}>7 \mathrm{dBZ}$ (corresponding to $R_{i}>0.11 \mathrm{~mm} \mathrm{~h}^{-1}$ ) for dataset I. Also shown are conditional PDFs for scans with $F<0.03$ (dashed line) and $F>0.03$ (dotted line). The $x$ axis is on a log scale. (b) The cumulative distribution of pixel rain rates $C\left(R_{i}\right)$ corresponding to the solid line in (a), with vertical lines indicating $C\left(R_{i}=0.4 \mathrm{~mm} \mathrm{~h}^{-1}\right)$ and $C\left(R_{i}=1 \mathrm{~mm} \mathrm{~h}^{-1}\right)$.

The time series also indicates that precipitation was almost continuously present, with only a $0.3 \%$ probability of finding scans without echoes, increasing to $10 \%$ for scans with echoes that cover less than 10 pixels $(F \approx 0.001)$. The chances of detecting precipitation anywhere in a given domain at a given time, however, is scale dependent (Tustison et al. 2001) and will be further addressed in a forthcoming paper. Using data from the spaceborne TRMM PR, Short and Nakamura (2000) also describe a near-constant background of shallow rainfall over the subtropical oceans, even at times of deep convection. The TRMM PR has an antenna beam that scans in a cross-track direction over $\pm 17^{\circ}$, making a $220-\mathrm{km}$ swath width from end to end, with a high vertical resolution $(250 \mathrm{~m})$. For the 17 TRMM overpasses during RICO, with the PR beam axis centered close to Antigua and Barbuda, surface echo fractions are comparable to values plotted in Fig. 4, on the order of 0.03 and less. However, the agreement of TRMM and SPol echo fractions by means of a scatterplot (not shown) is poor, possibly because the TRMM overpasses sample a subdomain of SPol but also because TRMM has a different horizontal resolution $(5 \mathrm{~km} \times 5 \mathrm{~km}$ mesh $)$ and a different sensitivity to

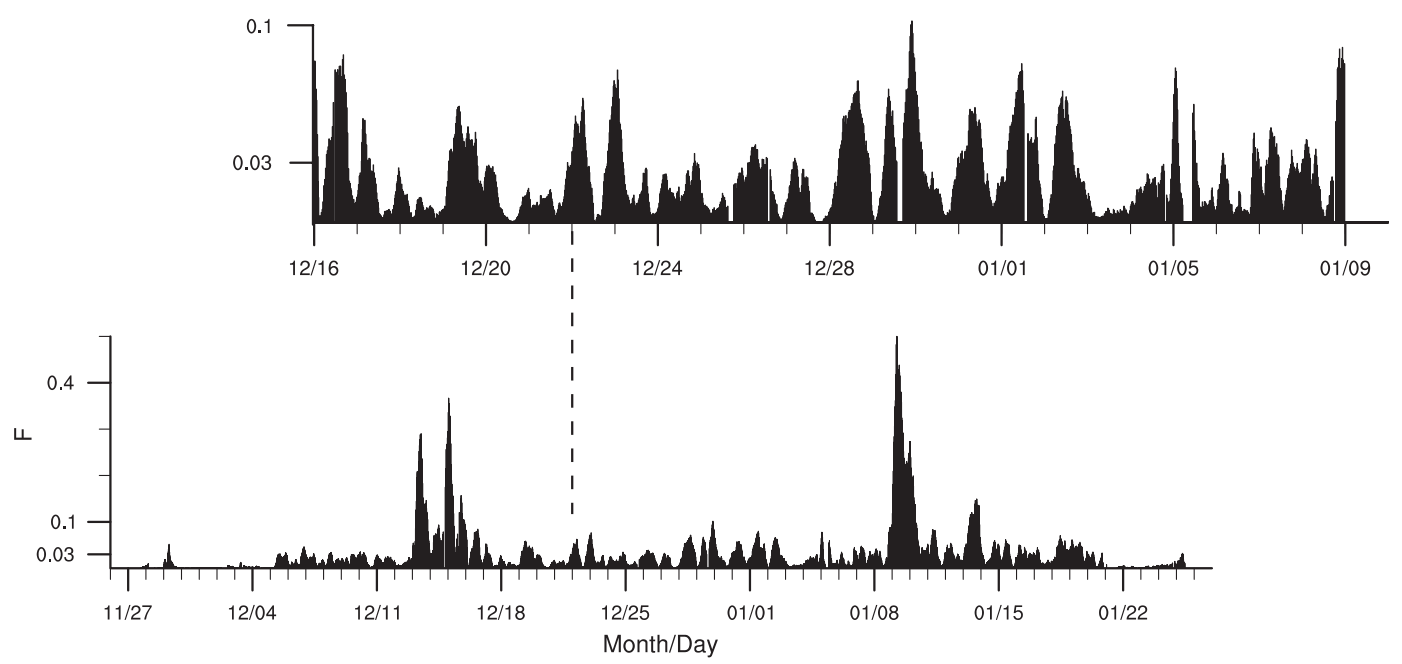

FIG. 4. The echo fraction $F$ of each radar scan of dataset I is plotted vs month and day during RICO. The inset at the top zooms in on the period between 16 December and 8 January. 
a)

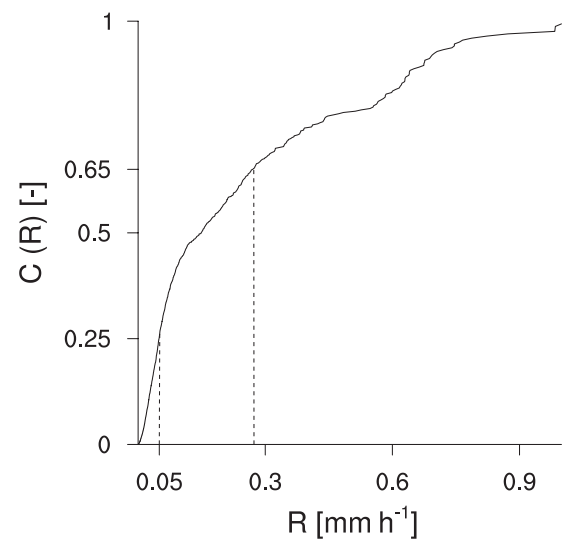

b)

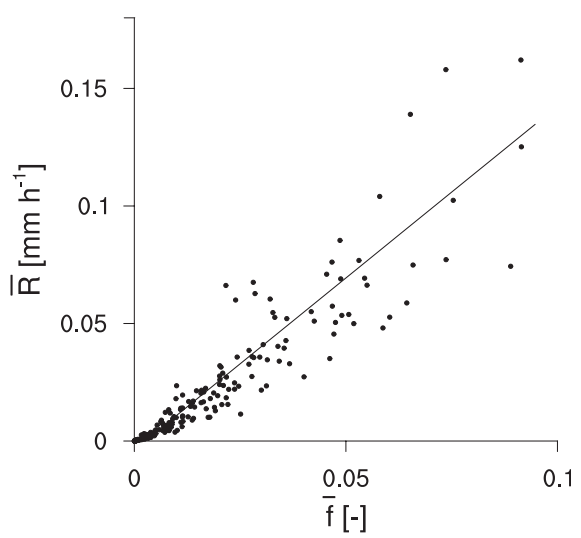

FIG. 5. (a) The cumulative distribution function of the area rain rate $C(R)$ using the radar scans in dataset I. (b) Six-hour averages of echo fraction $\bar{f}$ vs area rain rate $\bar{R}$ using dataset III.

low rain rates (only rain rates as low as $0.4-0.5 \mathrm{~mm} \mathrm{~h}^{-1}$ can be observed, yet many observed SPol rain rates are below this threshold; Fig. 3).

\section{3) Area-average rainfall}

Assuming that the rain rates in Fig. 3 are realistic, one may think of $1 \mathrm{~mm} \mathrm{~h}^{-1}$ as a significant rain shower, certainly more intense than drizzle. In terms of the energy budget of a cloud $\left(1 \mathrm{~mm} \mathrm{~h}^{-1} \approx 700 \mathrm{~W} \mathrm{~m}^{-2}\right)$, such a value is still small compared to the moisture flux carried by a cloud (approximately $5000-10000 \mathrm{~W} \mathrm{~m}^{-2}$ ), where the latter is estimated by dividing a typical moisture flux of $100 \mathrm{~W} \mathrm{~m}^{-2}$ by cloud core fractions of $1 \%$ or $2 \%$. Whether such values have a significant impact on the structure of the cloud-topped boundary layer on larger scales is yet to be evaluated, although LES studies show that rain rates of this order of magnitude lead to a lowering of the inversion height, as compared to nonprecipitating simulations (Stevens and Seifert 2008). In terms of the contribution of precipitation to heat and moisture budgets over a larger area, one should consider the rain intensity averaged over both raining and nonraining areas.

The area-average rainfall is estimated for dataset I as follows:

$$
R=\frac{\sum_{i=1}^{N}\left(I_{i} R_{i} r_{i}\right)}{\sum_{i=1}^{N} r_{i}},
$$

where $R_{i}$ is the pixel rain rate of each pixel $i$ and other symbols are as in Eq. (1).

On average, the area-average rainfall for dataset I $\left(\bar{R}^{\mathrm{I}}\right)$ is about $0.05 \mathrm{~mm} \mathrm{~h}^{-1} \approx 1.2 \mathrm{~mm} \mathrm{day}^{-1} \approx 35 \mathrm{~W} \mathrm{~m}^{-2}$, where the latter is about a factor of 3 smaller than a typical surface moisture flux [the other two $Z-R$ relations in section $3 \mathrm{~b}(2)$ lead to estimates of $\bar{R}$ that range from 0.03 to $0.07 \mathrm{~mm} \mathrm{~h}^{-1}$ ]. For individual radar scans of dataset II, $R$ is at most $\sim 0.3 \mathrm{~mm} \mathrm{~h}^{-1}$, which implies, given the cumulative distribution function of $R$ (Fig. 5), that shallow precipitation contributes a substantial part, say over $50 \%$, of the total precipitation during RICO. In comparison, the contribution of shallow to total precipitation as estimated by TRMM ranges up to 22\% (Short and Nakamura 2000). Because of resolution and sensitivity differences between TRMM and SPol, such values cannot be compared directly. Also, the estimates in Short and Nakamura (2000) are based on a much larger region (the subtropical oceans) and longer time period (both winter and summer seasons) and include only echoes with tops mostly below $3 \mathrm{~km}$, whereas clouds during RICO often had tops reaching up to $4 \mathrm{~km}$ that likely contributed considerably to the total precipitation.

Ideally the variability in precipitation during RICO is addressed from area-average rain rates, which depend on both the echo fraction and the intensity of individual pixels, where the latter two are not necessarily uncorrelated. Clouds with different dimensions may produce different rain intensities; for instance, deeper clouds may rain more intensely, and if these clouds have greater horizontal dimensions, and a higher cloud fraction, one may expect more intense rain rates on scans with higher echo fractions. Similarly, shallow clouds may correspond to low echo fractions and a higher probability of weak rain rates. The latter is somewhat evident in the previously introduced Fig. 3, which also plots conditional probability density functions of rain rates for scans with $F<0.03$ (dashed line) and $F>0.03$ (dotted line). However, overall the PDFs suggest that a similar range of rain rates is sampled irrespective of $F$. Because, as 


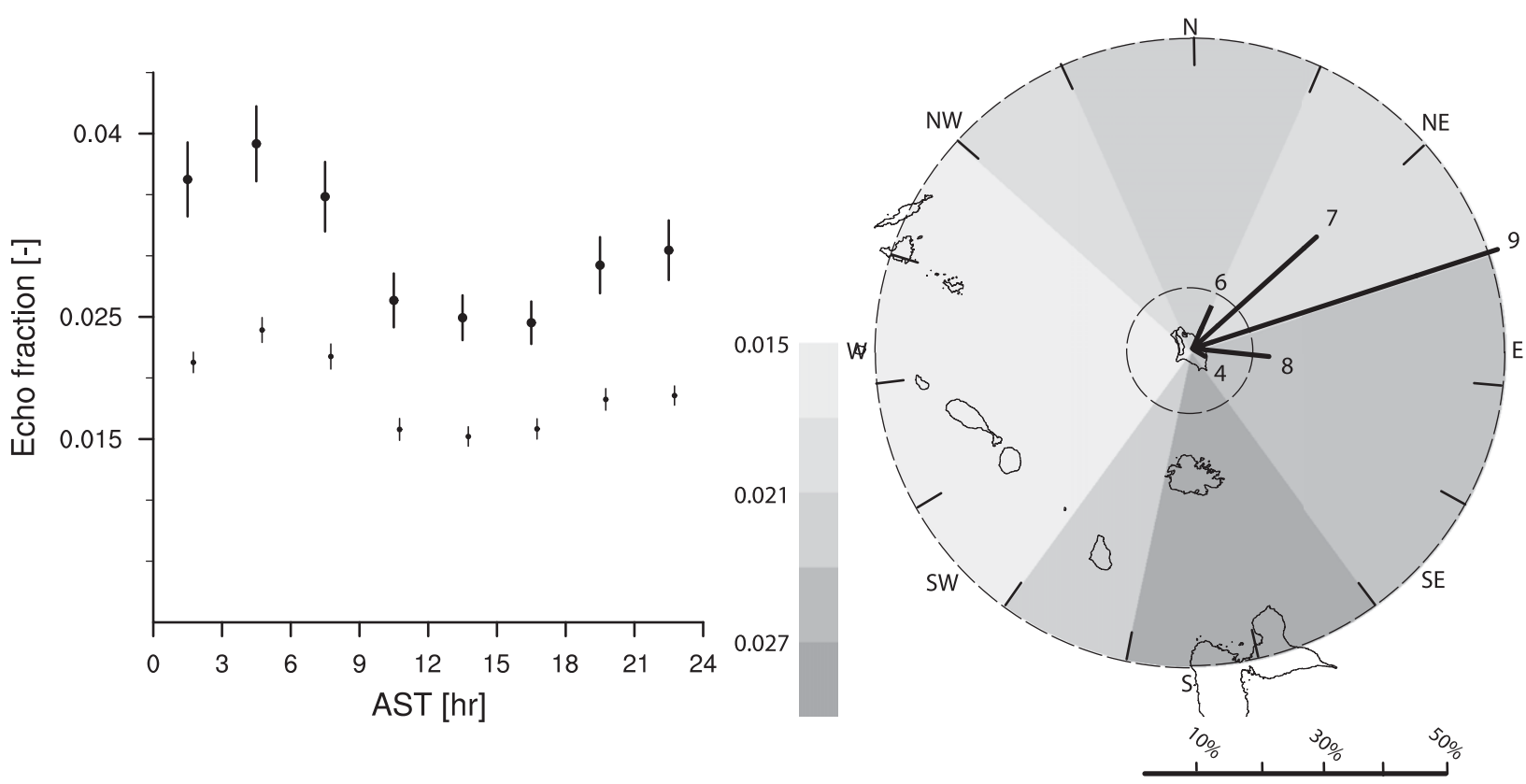

FIG. 6. (left) The mean echo fraction for 3-h bins is plotted against local Atlantic Standard Time (AST), with the large dots denoting dataset I and the small dots dataset II. The bars are the mean and uncertainty in the estimate of the mean $(\sigma / \sqrt{N})$, where $N$ equals the number of scans. (right) The mean echo fraction (indicated by the grayscale) for 15 radar segments for dataset II. The wind rose indicates the frequency of wind direction during RICO as measured by the length of the thick horizontal lines, with mean wind speed printed at the end of each line.

recognized in early studies (Doneaud et al. 1984), $F$ and $R$ are well correlated (Fig. 5b), we use echo fraction as a proxy for rainfall in the remaining analysis. By doing so, we circumvent the errors introduced by estimating rain rates without applying a correction for the range (height) dependency [as discussed in section $2 \mathrm{a}(1)$ ] and the $Z-R$ uncertainty.

\section{b. Temporal and spatial variability}

Even for the undisturbed days, a substantial variability in precipitation is seen, with the echo fraction routinely changing in just a day or less (Fig. 4). If it is not random, what regulates this variability? May it be attributed to a diurnal cycle? And how do statistics differ for different segments of the radar domain?

Distinct diurnal cycles with an early morning maximum in precipitation have been observed in several studies on deep convection (Nesbitt and Zisper 2003; Gray and Jacobson 1977). Although it is unclear whether the mechanisms proposed for diurnal cycles apply to shallow convection, Fig. 6 (left) indicates morning peaks and afternoon minima in precipitation, even for the undisturbed days. Plotted are 3-h average echo fractions versus Atlantic standard time (AST). The large and small dots correspond respectively to datasets I and II. With this diurnal cycle in mind, one can indeed observe early morning peaks for some days in Fig. 4, but the occurrence of this diurnality seems to wander somewhat.

The mean echo fractions of 15 segments of the radar domain for dataset II are plotted in Fig. 6 (right). Higher echo fractions are evident in the south and southeast segments and perhaps an island shadow with less precipitation downwind of Barbuda. As indicated by the wind rose, the mean flow tended to be northeasterly, yet several periods with more east southeasterly flow were present. The disturbed days (excluded from this figure) are characterized by slightly more southeasterly flow (Table 1) and would lead to an even more dominant maximum in precipitation south of Barbuda. The overall mean echo fraction of the $\left(90^{\circ}\right)$ northeast area is $\bar{f}^{\mathrm{II}}=0.018$, close to the mean echo fraction of the full domain $\bar{f}^{\mathrm{II}}=0.02$. As described in the methodology (2b), the remainder of our study focuses on the northeast segment, which does not appear unrepresentative of the statistics of the full domain.

\section{Meteorological environment}

The variability in the meteorological environment is explored by looking at changes in the vertical structure of the lower atmosphere and various characteristics of the cloud-topped boundary layer, such as surface fluxes, between periods of low versus high echo fraction. 

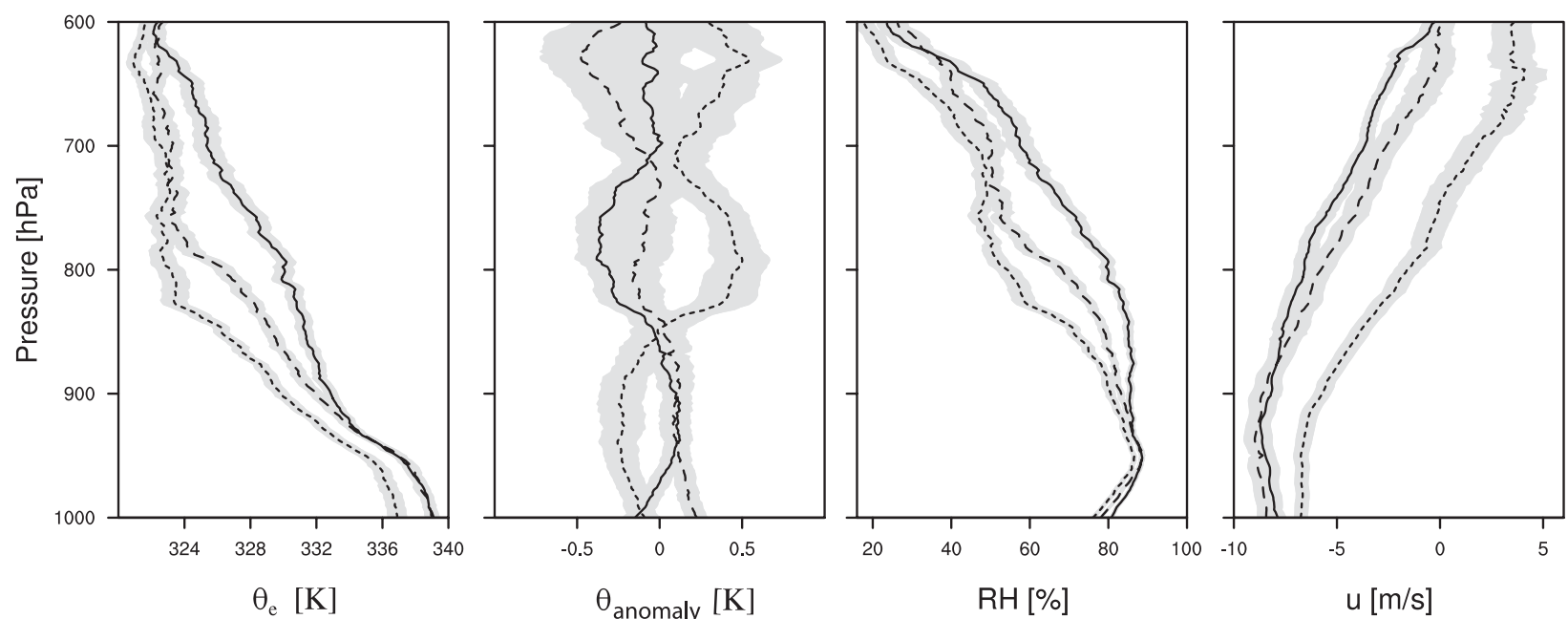

FIG. 7. Mean profiles of (left to right): $\theta_{e}, \theta-\bar{\theta}$, RH, and $u$ (with the uncertainty of the mean as a shaded area) for three composites: $0<\bar{f}<0.008$, with $\langle\bar{f}\rangle=0.003$ (dotted line); $0.008<\bar{f}<0.03$, with $\langle\bar{f}\rangle=0.014$ (dashed line); and $\bar{f}>0.03$, with $\langle\bar{f}\rangle=0.05$ (solid line). About 66 soundings are used in each composite.

\section{a. Atmospheric profiles}

Three composite profiles of equivalent potential temperature $\theta_{e}$, the potential temperature anomaly $(\theta-\bar{\theta}$, where $\bar{\theta}$ is the mean sounding of dataset III), relative humidity (RH), and zonal wind speed $u$ are plotted in Fig. 7. Given the small variations in $\theta, \theta_{e}$ variations mostly reflect variations in specific humidity. The dotted, dashed, and solid lines can be interpreted respectively as the vertical structure of the atmosphere during periods of little or no, moderate, and widespread precipitation. Profiles are only shown up to $600 \mathrm{hPa}$, corresponding to the level at which the dropsondes were released. The shaded areas represent the uncertainty in the estimate of the mean: $\sigma / \sqrt{(N)}$, where $N$ is the number of soundings in each composite, assuming that deviations of the mean are normally distributed. The composites reveal that deeper and moister layers are present at times of more rain, with differences of up to $10 \%$ among, for instance, the three relative humidity profiles.

Based on our inspection of the $\theta_{e}$ profiles, the largest differences in specific humidity between periods of little (dotted) and moderate precipitation (dashed) are confined to the layer below $800 \mathrm{hPa}$. Between moderate and widespread (solid) precipitation periods, differences in specific humidity are most pronounced from cloud base (here estimated at about $950 \mathrm{hPa}$ ) up to $600 \mathrm{hPa}$. The sensitivity of shallow precipitation to humidity has been noted in a recent LES study, where a $2 \mathrm{~g} \mathrm{~kg}^{-1}$ increase in the initial profiles of free tropospheric humidity led to surface rain rates at least 5 times as high (Stevens 2007). The presence of deeper and moister layers during periods with (heavier) precipitation has also been described in observational studies of deep convection (Bretherton et al. 2004; Holloway and Neelin 2009).

The profiles of $u$ indicate that stronger easterlies are present from the surface up to $600 \mathrm{hPa}$ during periods with moderate precipitation, as compared to periods with little precipitation. The differences are far less pronounced, however, when precipitation is further enhanced (between the second and third composite). Differences in the meridional wind speed are minor and therefore not shown.

A relation between precipitation and the atmospheric thermal structure is less clear and because differences are hard to distinguish otherwise, potential temperature profiles are shown as anomalies. The profiles are overall similar, but the first composite (dotted line) shows a more stable layer near $850 \mathrm{hPa}$. Also note that the third composite (solid line) is slightly colder near the surface, which may reflect cold pools created by evaporation of precipitation.

To further address the diurnal cycle for undisturbed periods, composite soundings for the early morning (after midnight but well before sunrise) versus early afternoon soundings were compared. The results are consistent with Fig. 7 (i.e., the mornings are slightly more humid); however, the differences are not large enough to be statistically significant and are therefore not shown.

\section{b. Deeper clouds, more rain?}

Deeper clouds with a higher (cloud top) liquid water content may rain more, as shown both in early studies of precipitating shallow cumulus (Austin 1948; Byers and Hall 1955) and in more recent radar (Knight and Miller 1998) and LES studies (Stevens and Seifert 2008). Figure 7 

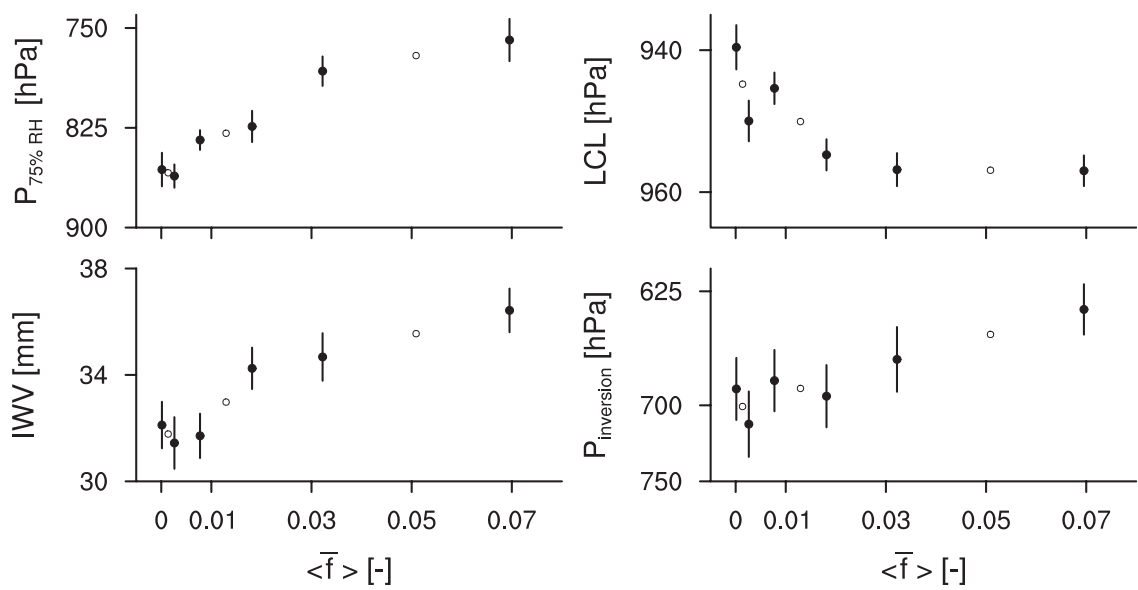

FIG. 8. Three composites (open circles), as well as six composites (filled circles) of: the pressure level at which $\mathrm{RH}=75 \%$, the integrated water vapor, the lifting condensation level, and the pressure level at maximum $d \theta / d z$ (the inversion) against $\langle\bar{f}\rangle$. Error bars denote the uncertainty in the estimate of the mean. Slightly more than 30 soundings are used in each of the six composites.

indicates that at times of more rain, the environment is more humid and humidity variations are more pronounced at levels above cloud base as compared to times of little rain. Because entrained environmental air that is more humid is less effective at inducing cooling (through evaporation of liquid water) and drying, this suggests that entrainment plays an important role in promoting greater parcel buoyancies, deeper clouds, and hence more rain in an environment with moister (cloud) layers. To emphasize that moister layers are also deeper layers, the first pressure level above $950 \mathrm{hPa}$ at which a relative humidity of $75 \%$ is crossed is calculated for each individual sounding of dataset III, averaged into composites based on $\bar{f}$ and plotted as circles against the composite mean $\langle\bar{f}\rangle$ (Fig. 8a). Three composites (open circles) are shown to facilitate a comparison with the three composite profiles, but to reveal more detail six composites (filled circles) are shown as well, with error bars denoting the uncertainty of the mean.

The integrated water vapor (IWV) over a 1000-200$\mathrm{hPa}$ layer (excluding $\mathrm{C} 130 \mathrm{C}$ soundings for which only data with pressures greater than $600 \mathrm{hPa}$ is available) increases substantially with echo fraction as well (Fig. $8 \mathrm{~b})$. Again the analogy with analyses of precipitating deep convection is worth mentioning: adopting a similar approach with sounding profiles over the island Nauru in the western tropical Pacific, Holloway and Neelin (2009) show that most of the variability in the humidity profiles, when conditioned on precipitation, is in the lower free troposphere and little is in the boundary layer, which in our case is principally evident between the second and third composite profile (Fig. 7). In their data, precipitation increases slowly with IWV up to about $65 \mathrm{~mm}$, followed by a sharp increase in precipitation for higher IWV. During RICO, $65 \mathrm{~mm}$ is about the upper limit of IWV values, consistent with the much smaller amounts of precipitation observed in this region compared to the region of their analysis.

The lifting condensation level, calculated from the average temperature and humidity over a $100-m$ layer above the sea surface, is lower with increasing precipitation. This is less pronounced for high $\langle\bar{f}\rangle$, consistent with the composite profiles that indicate minor differences in specific humidity in the lower (subcloud) layers between the second and third composite. Composites of the level of maximum $d \theta / d z$, which can be used as an indicator of the inversion height and cloud top, shift to greater altitudes with increasing precipitation. Although the signal is small, the shift of this level, in particular at higher $\langle\bar{f}\rangle$, may indicate the importance of changes in large-scale subsidence.

Clouds are indeed deeper, with increased cloud fractions at all levels, during periods with more rain. This is most evident in lidar data from the free tropospheric circles flown by the $\mathrm{C} 130$. Instead of the probability distribution of cloud top height, the cumulative probability distribution is plotted, which (assuming that cloudy air is present at all heights below a detected cloud top) is equivalent to the cloud fraction (Fig. 9). The data are averaged into two composites: those circles identified as "dry" (dashed line) and "wet" (solid line), for which the criteria are $\bar{f}<0.02$ and $\bar{f}>0.02$, respectively. The absolute cloud fraction is sensitive to the chosen lidar sensitivity threshold, particularly near cloud base where many thin clouds and significant aerosol backscatter can be expected. However, the qualitative differences 


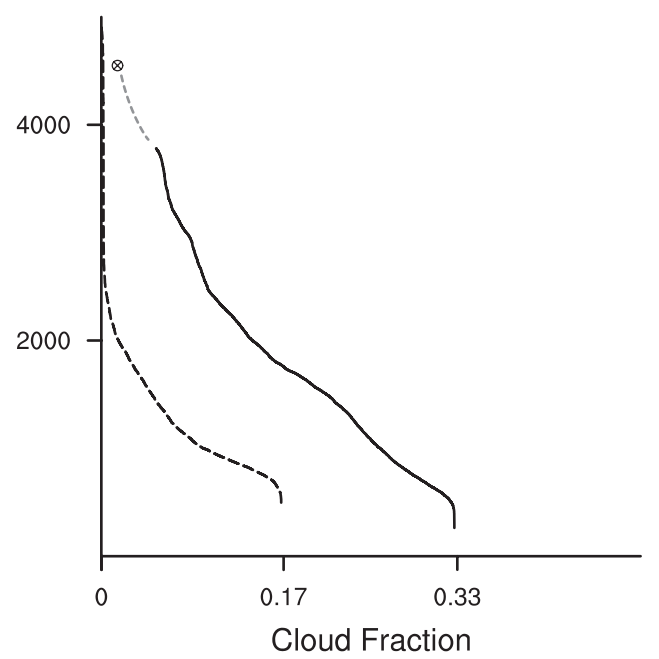

FIG. 9. Vertical profiles of cloud fraction derived from lidar data. The solid line represents all free tropospheric circles identified as "wet" $(\bar{f}>0.02$ with $\langle\bar{f}\rangle=0.05)$ and "dry" $(\bar{f}<0.02$ with $\langle\bar{f}\rangle=0.007)$. The $\otimes$ symbol indicates the condensate fraction for the wet circles as measured by the in situ probes of the aircraft, which is zero for the dry circles.

between the wet and dry circles, and in particular the inferred cloud heights, do not depend on this threshold.

\section{c. Surface fluxes and winds}

Throughout RICO, SSTs decreased gradually from roughly 300 to $299.3 \mathrm{~K}$. Because precipitation at the beginning of the field campaign was slightly less prevalent than during January (Fig. 4), there is some evidence of lower SSTs corresponding to higher echo fractions, yet absolute differences are rather small. This is shown in Fig. 10 where three composites (open circles) as well as six composites (filled circles) of nearsurface properties are plotted against $\langle\bar{f}\rangle$. Similar to the zonal wind profiles, wind speeds at $10 \mathrm{~m}$ increase with echo fraction, most pronouncedly at lower echo fractions when $\langle\bar{f}\rangle<0.02$. It should be noted that the range of wind speeds plotted here is small but that a similar behavior holds for daily average wind speeds, a point we return to later. Changes in wind direction are also small, although precipitation appears scarcer for northerly winds and increases as the winds become more easterly.

The surface fluxes, particularly the latent heat flux, remain essentially constant for $\langle\bar{f}\rangle<0.02$ despite increasing wind speeds. This suggests that the latter offsets decreasing differences in air-sea temperature and humidity. It may also indicate a tendency for stronger winds from the (south)east, advecting warmer and moister air masses from regions with higher SSTs, but overall the variability in wind direction is small. For higher echo fractions, $\langle\bar{f}\rangle>0.02$, the sensible heat flux increases despite a decrease in wind speed, and the latent heat flux decreases. This may indicate cooling and moistening due to evaporation of precipitation below cloud base. However, precipitation is not the only factor; the flux of $\theta_{e}$, which is approximately conserved under evaporative cooling and moistening, also decreases.

The variability in surface $\theta_{e}$ fluxes appear largely regulated by subcloud layer $\theta_{e}$ and wind speed. The decrease in $\theta_{e}$ flux is only slightly weaker if SSTs are held constant in the derivation of the fluxes. One may question whether the strong increase in sensible heat flux at high echo fractions is affected by using land-based temperature measurements. Although the ISFF sensible heat fluxes are indeed on average about $2-5 \mathrm{~W} \mathrm{~m}^{-2}$ higher than open sea RVSJ fluxes, they overestimate low and high flux cases. Furthermore, a similar behavior is observed using only RVSJ fluxes during January.

\section{d. Relations among winds, humidity, and echo fraction}

From the data composites, the winds and humidity in particular are seen to vary with echo fraction, but does humidity also vary with wind? To help answer this question, relations among daily averages of the winds, echo fraction, and humidity are explored by means of multivariate scatterplots (Fig. 11). Focusing on daily averages facilitates a comparison among different datasets with different temporal resolutions. The plots include a great deal of information, but we believe that showing relations in more than one dimension is worthwhile.

The left two panels in Fig. 11 plot wind speed versus echo fraction, where the size of the dot is a measure of the mean relative humidity over a 900-700-hPa layer from soundings (averaged over all available soundings on a given day). The shading indicates ranges of wind direction based on its average $\left(67^{\circ}\right)$ and half a standard deviation $\left(13^{\circ}\right)$. The winds are derived from radial velocity data (with the same temporal frequency and spatial coverage as echo fraction) and thus are representative of the large-scale wind within the subcloud and lower cloud layer. A much larger range of values is shown here compared to the ISFF composite winds in Fig. 10. The right two panels complement the left two, but here the mean relative humidity is plotted on the $y$ axis and the size and thickness of the squares vary with echo fraction. The two bottom panels include days with an average echo fraction less than $0.02\left(\bar{f}^{d}<0.02\right)$, whereas the top panels include days with an average $>0.02$.

To make it easier to discuss the apparent different behavior observed in the top versus the bottom panels, we may refer to the changes in meteorology with changes in echo fraction in terms of two regimes: a sparse precipitation regime 1 in the bottom two panels, displaying 

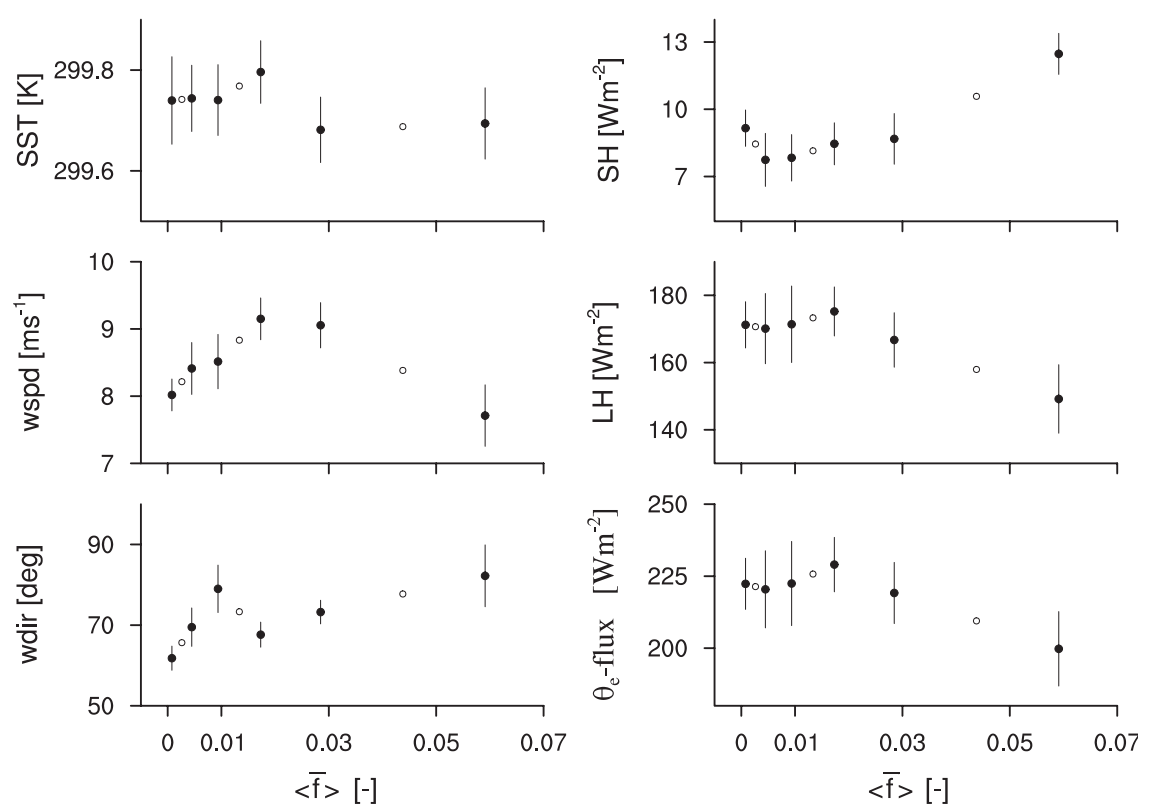

FIG. 10. As in Fig. 8, but for three and six composites of SST, wind speed, wind direction at 10 AGL (ISFF data), and the sensible (SH), latent (LH) and $\theta_{e}$ fluxes against $\langle\bar{f}\rangle$. Slightly more than 30 data points are used in each of the six composites.

variability between periods of little and moderate precipitation, and a widespread-precipitation regime 2 in the top two panels, displaying variability between periods of moderate and widespread precipitation.

For regime 1, echo fraction appears to increase with wind speed and this relation $(R=0.51$; bottom left panel) seems to hold regardless of wind direction, although this is perhaps most evident for easterly and southeasterly winds. There is some evidence from the bottom right panel that higher wind speeds correspond to higher humidities, in particular for wind directions close to average (in dark gray), yet there are some days with high humidities despite low wind speeds. A wind speed echo fraction relation appears less evident for regime $2(R=-0.38$, solid regression line; top left panel) and is essentially absent if one day with $\bar{f}^{d}=$ 0.0072 is excluded ( $R=-0.12$; dashed regression line). Regime 2 clearly has the highest relative humidities, indicated by the thick dots, yet a correlation between wind speed and humidity is less evident here. Including the 6 days with disturbed conditions (Table 1) and echo fractions of 0.09 and higher would not change this finding.

\section{Discussion}

What is the nature of the relationship between wind speed and humidity, and between wind speed and precipitation? If not wind speed, what are other possible controlling factors on precipitation? A possible mechanism through which wind speed influences humidity is enhanced surface evaporation, which may lead to a greater population of cumulus clouds and subsequently more (upward) mixing of moisture between the subcloud and the cloud layer, promoting the development of even deeper clouds, with higher chances of precipitation. On the other hand, weaker large-scale subsidence (less subsiding warm and dry air) can lead to a greater boundary layer depth and a more humid environment, which also promotes deeper clouds. Using (equilibrium) bulk theory, section 5a further explains these ideas that underlie our hypothesis that boundary layer humidity (and hence precipitation) is regulated by subtle fluctuations in wind speed as well as subsidence. We should be mindful, however, that the aerosol will covary with the meteorological environment and may also play a role in regulating the precipitation efficiency of clouds. For instance, increasing winds can lead to higher concentrations of marine sea salt particles from breaking waves. In section $5 \mathrm{~b}$ we speculate on possible aerosol effects and describe why we believe the major variability in precipitation during RICO is not controlled by the aerosol.

\section{a. Bulk theory}

A distinction in two regimes (as introduced in section 4d) may also be used when interpreting the composite profiles and surface flux data from a bulk perspective 

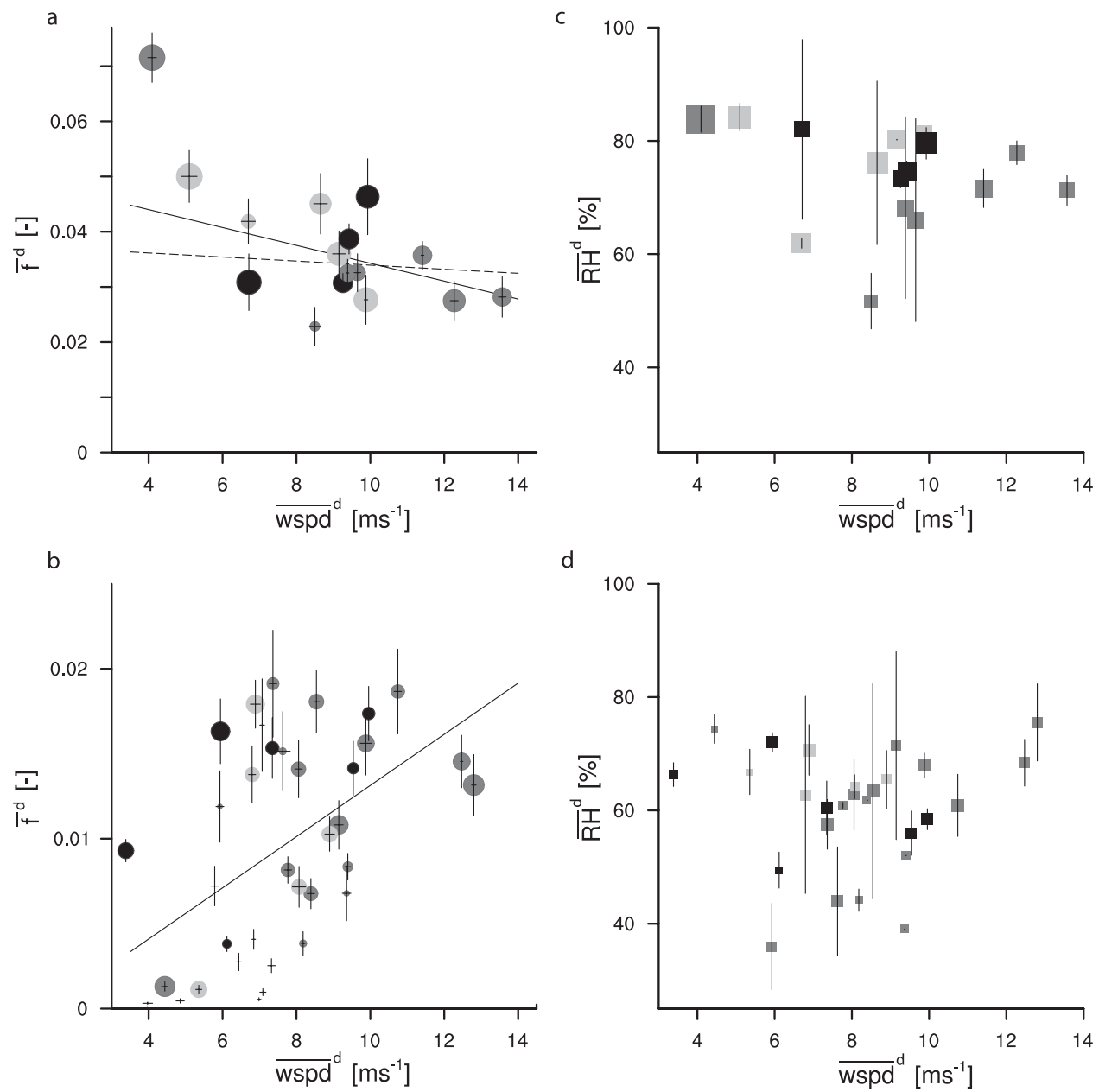

d
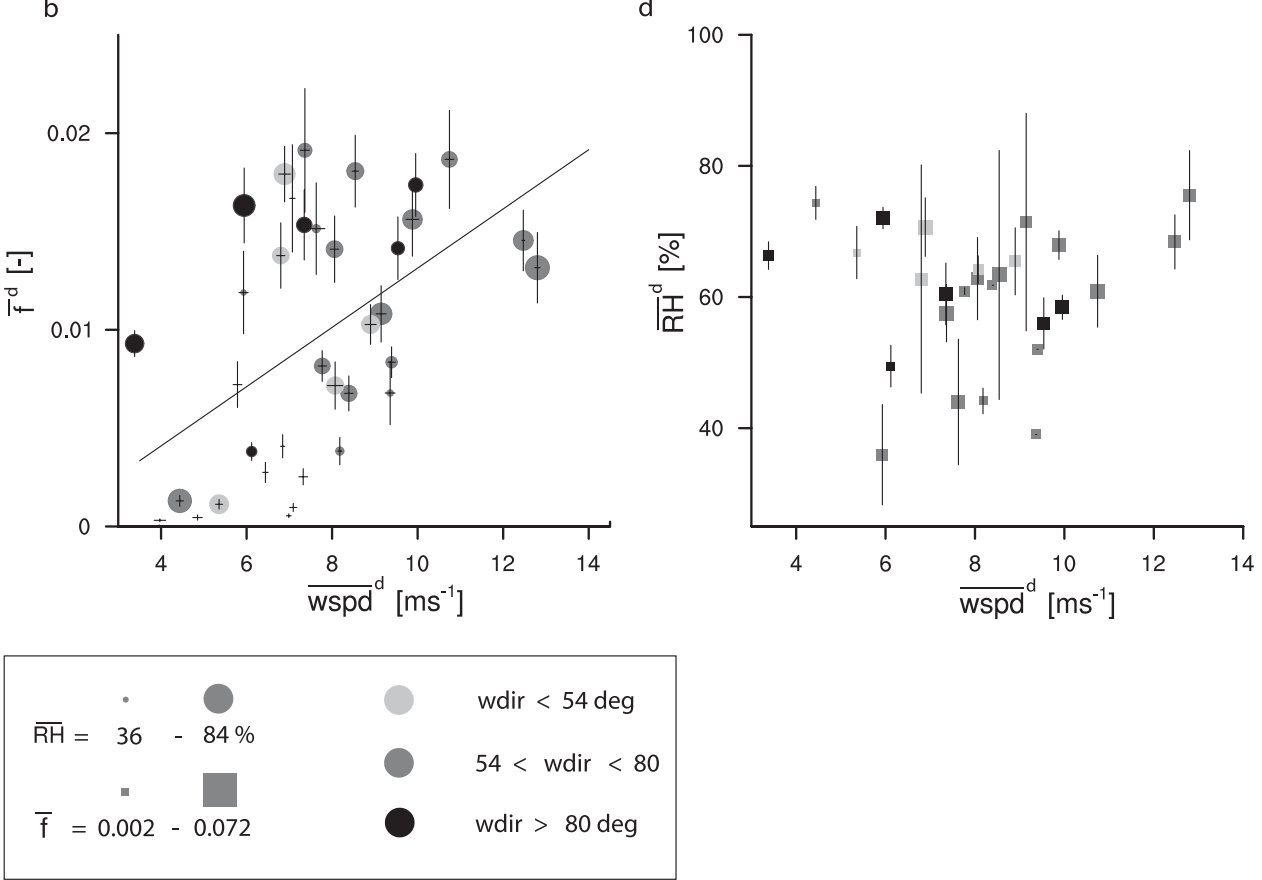

FIG. 11. (a) Daily average echo fraction $\bar{f}^{d}$ is plotted vs daily wind speed (average over a 1-km layer centered in the upper subcloud layer from SPol radial velocity data) for $\bar{f}^{d}>0.02$ with vertical and horizontal bars as the uncertainty of the mean. Size of the dot varies according to the mean RH over a 900-750-hPa layer from soundings, and shading varies with the mean wind direction. In absence of soundings, just an error bar is plotted. The 6 days in Table 1 are excluded. (b) As in (a), but for $\bar{f}^{d}<0.02$. (c) As in (a), but the size and thickness of the squares vary according to $\bar{f}^{d}$ with $\bar{f}^{d}>0.02$, and the mean relative humidity is plotted on the $y$ axis. (d) As in (c), but for $\bar{f}^{d}<0.02$.

and is illustrated in Fig. 12. In particular, the $\theta_{e}$ profiles indicate a different behavior in terms of the location of most pronounced changes in humidity between minimally (dotted) versus moderately (dashed) precipitating periods (regime 1) and moderately versus widespread (solid) precipitating periods (regime 2). In summary, regime 1 corresponds to higher humidities and stronger easterlies, not only near the surface but throughout the entire lower atmosphere, with a $\theta_{e}$ flux that remains basically constant (Fig. 10). In regime 2, on the other hand, the variability in humidity is most pronounced at upper levels, whereas little difference in (near surface) winds is seen and the flux of $\theta_{e}$ decreases. An increase in the inversion height, however, is more pronounced for these cases (Fig. 8).

These findings support our idea that moistening is dominantly forced from the bottom part of the boundary layer (wind speed) versus the top part (subsidence). 

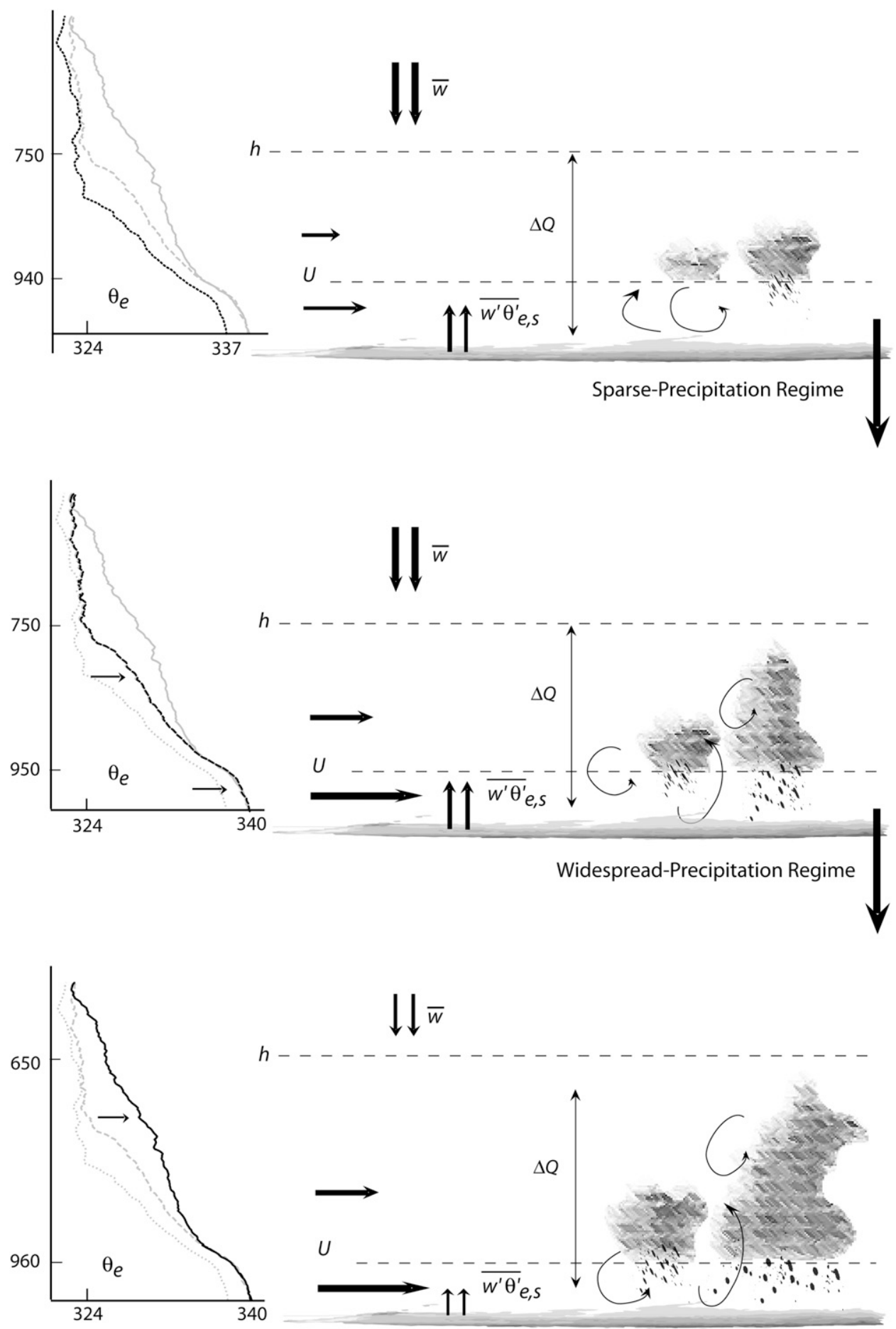

FIG. 12. Illustration of the processes in a bulk trade wind layer in equilibrium: wind speed $(U)$, surface $\theta_{e}$ flux $\left(\overline{w^{\prime} \theta_{e}^{\prime}}\right)$ subsidence velocity $(\bar{w})$, and the radiative flux difference $(\Delta Q)$ across the boundary layer depth (here denoted by $h$ ). Composites (top) 1 and (middle) 2 constitute the sparse precipitation regime; similarly, the composites (middle) 2 and (bottom) 3 constitute the widespread precipitation regime; $\theta_{e}$ profiles indicate the location of most pronounced variations in specific humidity. 
This idea may be reconciled with the observed flux behavior using bulk equilibrium theories of equatorward transport of air masses over the (subtropical) ocean by the trade winds, such as described in Betts and Ridgway (1989). In bulk theory, clouds (and precipitation) are the link among surface forcing (the surface fluxes), radiative cooling within the convective boundary layer, and subsiding tropospheric warm and dry air, which in equilibrium define the heat and moisture balance in the cloud-topped boundary layer. In view of such an equilibrium, and assuming for simplicity a constant radiative cooling rate, envision a column of air that is advected at an increasing speed in the first regime, leading to enhanced evaporation. Assuming that subsidence varies little, a heat and moisture balance with unchanging equilibrium surface fluxes can be maintained only by decreasing differences between surface and subcloudlayer temperature and humidity (the sparse precipitation regime 1 in Fig. 12). In the widespread precipitation regime 2, variability in the winds is present but not dominant, and weaker subsidence may explain the observed moistening and deepening of the cloud layer, which, in equilibrium, implies lower surface fluxes.

Worth noting is that wind speed was shown to explain a significant part of daily rainfall variability in the Pacific ITCZ from 4 yr of satellite retrieved data over $2.5^{\circ}$ grid boxes in Back and Bretherton (2005). The suggested ideas through which wind speed influences precipitation (for deep convection), such as boundary layer quasiequilibrium theory (Raymond 2005), are in some ways similar to the mechanisms proposed here for a shallow layer using bulk theory. Work is ongoing to explore the extent to which such theories are similar and provide good explanations of precipitating shallow convection.

The anomalous subsidence necessary to explain the differences between the second and first $\theta_{e}$ profile in regime 1 is about $0.02 \mathrm{~Pa} \mathrm{~s}^{-1}$ (if occurring over the course of a day), compared to $0.04 \mathrm{~Pa} \mathrm{~s}^{-1}$ for the third and second $\theta_{e}$ profile in regime 2. Because a typical subsidence rate for the Atlantic trade wind regions is about $0.05 \mathrm{~Pa} \mathrm{~s}^{-1}$ (Holland and Rasmusson 1973), one may infer that variability in subsidence plays a larger role in regime 2. In an effort to explore these ideas, reanalysis data from the Regional Atmospheric Climate Model (RACMO) were used, yet this proved challenging. For instance, sea surface pressures did not respond in a systematic way to reveal a possible covariability in subsidence and the strength and direction of the mean wind field.

\section{b. Aerosol effects}

An enhanced contribution of sea salt particles to marine aerosol can be expected at stronger winds from breaking of waves. This appears most evident at larger sizes, leading to more so-called giant nuclei (GN; radii roughly $>1 \mu \mathrm{m}$ ) (Woodcock 1953), although production of sea salt particles in all sizes from 0.01 to $10 \mu \mathrm{m}$, peaking at $0.03 \mu \mathrm{m}$, has been observed as well, indicating a significant contribution of small sea salt particles to nuclei-mode aerosols (Clarke et al. 2003). Aerosol particles with radii $>0.2 \mu \mathrm{m}$ during a low-wind speed RICO research flight were found to be mostly sea salt, but those with radii $<0.2 \mu \mathrm{m}$ were ammonium sulfate (Peter et al. 2008). However, measurements of the composition of cloud droplet nuclei in nonprecipitating marine clouds from several field campaigns, including one RICO flight, indicate that preferred nuclei types are composed of salts (Twohy and Anderson 2008). Whether sea salt contributed appreciably to the number of cloud condensation nuclei (CCN) for RICO in general, either directly or by coagulation or heterogeneous reactions with other aerosol particles such as sulfates, needs more investigation. From wind data of flight-averaged cloud droplet spectra near cloud base and CCN measured at $100 \mathrm{~m}$ for 12 different RICO flights, a strong correlation between wind speed and concentration of GN is indeed found, as well as a much weaker correlation between wind speed and CCN (Colón-Robles et al. 2006; Hudson and Mishra 2007).

GN may accelerate collision-coalescence processes within clouds and promote warm rain formation. On the other hand, more $\mathrm{CCN}$ can reduce the efficiency of collision-coalescence processes (all else being equal) and slow down warm rain formation. One of the major questions that motivated the RICO field campaign was in fact: What is the role of $\mathrm{CCN}$ versus GN in the fast onset of warm rain in shallow cumuli?

In studying the development of precipitation in trade wind cumulus during RICO using differential reflectivity data at S band, Knight et al. (2008) find no evidence that ultragiant aerosols initiate coalescence during rain onset, in strong contrast with a similar study for cumulus over land. Moreover, despite the strong correlation between wind speed and GN for the 12 RICO flights, ColónRobles et al. (2006) and Hudson and Mishra (2007) find an inverse correlation between wind speed and the number of large cloud droplets near cloud base. Although generally the largest droplets form at cloud top where more liquid water is present (to the extent that droplet concentrations remain roughly constant with height), both studies take the number of large droplets as an indicator for the efficiency of warm rain formation. Hudson and Mishra (2007) also show that a factor of 4 variability in $\mathrm{CCN}$ (from 50 and $200 \mathrm{~cm}^{-3}$ ) has the dominant influence on the number of large cloud droplets. These findings are thus consistent with the general idea that as long as $\mathrm{CCN}$ concentrations are low (i.e., in 
clean maritime regions), the influence of GN on the formation of raindrops may not be critical; likewise, they are in agreement with modeling studies that show that as long as $\mathrm{CCN}<600 \mathrm{~cm}^{-3}$, any added GN have no appreciable effect on the onset of rain and the total precipitation on the ground (Teller and Levin 2006).

We consider these results compelling evidence that the positive wind speed-precipitation relationship found in what we have called the sparse precipitation regime (Fig. 11b) is not caused by GN. To the extent that CCN scales with wind speed and rain production is more efficient in a weak wind environment, as hypothesized by Colón-Robles et al. (2006), our data do not provide evidence for a major role of $\mathrm{CCN}$ in controlling precipitation; that is, we do not find an inverse wind speedprecipitation relationship. In the second (widespread precipitation) regime, no significant relationship is present at all (Fig. 11a) and no particular role may be attributed to either CCN or GN. The aerosol may well play a role by influencing the intensity of precipitation or by setting the cloud depth at which rain forms, in particular for individual clouds. However, we speculate that in terms of its (large scale) areal coverage, precipitation in the undisturbed trades is more strongly influenced by subtle variations in the meteorological environment.

\section{Conclusions}

Precipitation from shallow cumulus has been estimated using observations from a ground-based radar during the 2-month RICO field study, set in a typical trade wind region, and compared to the meteorological environment measured by sounding, surface flux, and airborne lidar data. A wide range of rain rates is observed, with one third of the rain rates exceeding $1 \mathrm{~mm} \mathrm{~h}^{-1}$. The contribution of shallow to total precipitation during RICO is substantial, ranging up to at least $50 \%$. Given its minimum detectable rain rate of $0.4 \mathrm{~mm} \mathrm{~h}^{-1}$, TRMM would have missed more than half of the precipitation in regions such as these. Over larger areas, variations in rain intensity appear to have a minor influence on the area-average rainfall, compared to the area covered by precipitation. For undisturbed days during RICO, the echo fraction is typically less than 0.1 , with an average of about 0.02 , which implies, given a typical cloud fraction of 0.1 to 0.2 , that about one tenth of the clouds are raining. A diurnal cycle in echo fraction is present, with a peak in precipitation in the early morning.

Within the size of the radar domain, a substantial variability in precipitation (in terms of the echo fraction) is observed. Periods with moderate precipitation, as compared to periods with little precipitation, are characterized by deeper and moister layers and stronger easterlies from the surface up to the free troposphere, but overall there is little change in the temperature structure and surface fluxes. Periods with more widespread precipitation reveal even higher humidities, mostly in the cloud layer and free troposphere (below $600 \mathrm{hPa}$ ). A clear increase in integrated water vapor is seen with increasing precipitation, as well as an increase of the inversion height. Clouds during periods of widespread precipitation reached up to $4 \mathrm{~km}$, about twice that of the maximum cloud top present during periods with little precipitation.

Our analyses suggest that a more humid environment promotes deeper clouds (with higher liquid water content) that rain more, where the humidity field itself is regulated by subtle variations in the strength of the mean wind field as well as by large-scale subsidence. The observed covariability in wind speed, humidity, and precipitation (similar to cases of precipitating deep convection) is considered compelling evidence that even subtle variations in the meteorological environment are a major control on precipitation. Because these effects are subtle and act in a way that confounds expected relationships between aerosol and precipitation, it may prove difficult to differentiate between the effects of aerosol and of the meteorological environment.

Acknowledgments. The authors wish to express their appreciation to Bob Rilling at NCAR for his helpful suggestions on the quality control of the SPolKa radar data. The first author would like to thank Margreet van Zanten and the Atmospheric Research Group at the Royal Netherlands Meteorological Institute (KNMI) for their help and hospitality throughout the course of this study. Thanks go to Chris Holloway for motivating conversations on our analysis, to Brian Medeiros and Robert Wood for careful comments on earlier versions, and to an anonymous reviewer who challenged us to think more deeply about aerosol-meteorology relationships, which greatly improved the manuscript. This work was supported by the NSF through Grant ATM00342625.

\section{REFERENCES}

Austin, G., R. Rauber, H. Ochs III, and L. Miller, 1996: Tradewind clouds and Hawaiian rainbands. Mon. Wea. Rev., 124, 2126-2151.

Austin, J., 1948: A note on cumulus growth in a nonsaturated environment. J. Meteor., 5, 103-107.

Back, L., and C. Bretherton, 2005: The relationship between wind speed and precipitation in the Pacific ITCZ. J. Climate, 18, 4317-4328.

Betts, A., and W. Ridgway, 1989: Climatic equilibrium of the atmospheric convective boundary layer over a tropical ocean. J. Atmos. Sci., 46, 2621-2641. 
Bony, S., J. L. Dufresne, H. Le Treut, J. J. Morcrette, and C. Senior, 2004: On dynamic and thermodynamic components of cloud changes. Climate Dyn., 22, 71-86.

Bretherton, C., M. Peters, and L. Back, 2004: Relationships between water vapor path and precipitation over the tropical oceans. J. Climate, 17, 1517-1528.

Byers, H., and R. Hall, 1955: A census of cumulus cloud height versus precipitation in the vicinity of Puerto Rico during the winter and spring of 1953-1954. J. Meteor., 12, 176-178.

Caesar, K., cited 2005: Summary of the weather during the RICO project. [Available online at http://www.eol.ucar.edu/rico.]

Clarke, A., V. Kapustin, S. Howell, K. Moore, B. Lienert, S. Masonis, T. Anderson, and D. Covert, 2003: Sea-salt size distributions from breaking waves: Implications for marine aerosol production and optical extinction measurements during SEAS. J. Atmos. Oceanic Technol., 20, 1362-1374.

Colón-Robles, M., R. Rauber, and J. Jensen, 2006: Influence of low-level wind speed on droplet spectra near cloud base in trade wind cumulus. Geophys. Res. Lett., 33, L20814, doi:10.1029/2006GL027487.

Doneaud, A., S. Ionescu-Niscov, D. Priegnitz, and P. Smith, 1984: The area-time integral as an indicator for convective rain volumes. J. Climate Appl. Meteor., 23, 555-561.

Fairall, C., E. Bradley, J. Hare, A. Grachev, and J. Edson, 2003: Bulk parameterization of air-sea fluxes: Updates and verification for the COARE algorithm. J. Climate, 16, 571-591.

Gray, W., and R. Jacobson Jr., 1977: Diurnal variation of deep cumulus convection. Mon. Wea. Rev., 105, 1171-1188.

Holland, J., and E. Rasmusson, 1973: Measurements of the atmospheric mass, energy, and momentum budgets over a 500kilometer square of tropical ocean. Mon. Wea. Rev., 101, 44-55.

Holloway, C., and J. Neelin, 2009: Moisture vertical structure, column water vapor, and tropical deep convection. J. Atmos. Sci., 66, 1665-1683.

Hudson, J., and S. Mishra, 2007: Relationships between CCN and cloud microphysics variations in clean maritime air. Geophys. Res. Lett., 34, L16804, doi:10.1029/2007GL030044.

Johnson, R., T. Rickenbach, S. Rutledge, P. Ciesielski, and W. Schubert, 1999: Trimodal characteristics of tropical convection. J. Climate, 12, 2397-2418.

Joss, J., and R. Lee, 1995: The application of radar-gauge comparisons to operational precipitation profile corrections. J. Appl. Meteor., 34, 2612-2630.

Knight, C., and L. Miller, 1993: First radar echoes from cumulus clouds. J. Atmos. Sci., 74, 179-188.

— mulus: Bragg and hydrometeor scattering. J. Atmos. Sci., 55, 2974-2992.

,$- \ldots$, and R. Rilling, 2008: Aspects of precipitation development in trade wind cumulus revealed by differential reflectivity at S band. J. Atmos. Sci., 65, 2563-2580.

Lau, K., and H. Wu, 2003: Warm rain processes over tropical oceans and climate implications. Geophys. Res. Lett., 30, 2290, doi:10.1029/2003GL018567.

Medeiros, B., B. Stevens, I. Held, M. Zhao, D. L. Williamson, J. G. Olson, and C. S. Bretherton, 2008: Aquaplanets, climate sensitivity, and low clouds. J. Climate, 21, 4974-4991.

Nesbitt, S., and E. Zisper, 2003: The diurnal cycle of rainfall and convective intensity according to three years of TRMM measurements. J. Climate, 16, 1456-1475.

Nuijens, L., 2005: Estimating precipitation from radar observations in the trade-wind cumulus region. M.S. thesis, Department of
Meteorology and Air Quality, Wageningen University and Research Center, 46 pp.

Peter, J., A. Blyth, B. Brooks, J. Mc.Quaid, J. Lingard, and M. Smith, 2008: On the composition of Caribbean maritime aerosol particles measured during RICO. Quart. J. Roy. Meteor. Soc., 134, 1059-1063.

Petty, G., 1999: Prevalence of precipitation from warm-topped cumulus clouds over eastern Asia and the western Pacific. J. Climate, 12, 220-229.

Rauber, R. M., and Coauthors, 2007: Rain in shallow cumulus over the ocean: The RICO campaign. Bull. Amer. Meteor. Soc., 88, 1912-1928.

Raymond, D., 2005: Regulation of moist convection over the west Pacific warm pool. J. Atmos. Sci., 52, 3945-3959.

Reynolds, R. W., N. A. Rayner, T. M. Smith, D. C. Stokes, and W. Wang, 2002: An improved in situ and satellite SST analysis for climate. J. Climate, 15, 1609-1625.

Schumacher, C., and R. Houze Jr., 2003: The TRMM precipitation radar's view of shallow, isolated rain. J. Appl. Meteor., 42, 1519-1524.

Short, D., and K. Nakamura, 2000: TRMM radar observations of shallow precipitation over the tropical oceans. J. Climate, 13, 4107-4124.

Siebesma, A. P., and Coauthors, 2003: A large-eddy simulation intercomparison study of shallow cumulus convection. J. Atmos. Sci., 60, 1201-1219.

Snodgrass, E., 2006: Precipitation characteristics from trade wind clouds during RICO derived from radar, satellite, and aircraft measurements. M.S. thesis, Department of Atmospheric Sciences, University of Illinois at Urbana-Champaign, $101 \mathrm{pp}$.

—, L. Di Girolamo, and R. M. Rauber, 2009: Precipitation characteristics of trade wind clouds during RICO derived from radar, satellite, and aircraft measurements. J. Appl. Meteor. Climatol., 48, 464-483.

Sobel, A., S. Yuter, C. Bretherton, and G. Kiladis, 2004: Largescale meteorology and deep convection during TRMM KWAJEX. Mon. Wea. Rev., 132, 422-444.

Stevens, B., 2007: On the growth of layers of nonprecipitating cumulus convection. J. Atmos. Sci., 64, 2916-2931.

- and A. Seifert, 2008: Understanding macrophysical outcomes of microphysical choices in simulations of shallow cumulus convection. J. Meteor. Soc. Japan, 86A, 143-162.

Teller, A., and Z. Levin, 2006: The effects of aerosols on precipitation and dimensions of subtropical clouds: A sensitivity study using a numerical cloud model. Atmos. Chem. Phys., 6, 67-80.

Tustison, B., D. Harris, and E. Foufoula-Georgiou, 2001: Scale issues in verification of precipitation forecasts. J. Geophys. Res., 106, $11775-11784$.

Twohy, C., and J. Anderson, 2008: Droplet nuclei in nonprecipitating clouds: composition and size matter. Environ. Res. Lett., 3, 1-9.

Woodcock, A., 1953: Salt nuclei in marine air as a function of altitude and wind force. J. Meteor., 10, 362-371.

Xue, H., and G. Feingold, 2006: Large-eddy simulations of trade wind cumuli: Investigation of aerosol indirect effects. J. Atmos. Sci., 63, 1605-1622.

,-- , and B. Stevens, 2008: Aerosol effects on clouds, precipitation, and the organization of shallow cumulus convection. J. Atmos. Sci., 65, 392-406.

Yin, B., and B. Albrecht, 2000: Spatial variability of atmospheric boundary layer structure over the eastern equatorial Pacific. J. Climate, 13, 1574-1592. 